This item was submitted to Loughborough's Research Repository by the author.

Items in Figshare are protected by copyright, with all rights reserved, unless otherwise indicated.

\title{
Methods for the quantification of pseudo-vibration sensitivities in laser vibrometry
}

PLEASE CITE THE PUBLISHED VERSION

http://dx.doi.org/10.1088/0957-0233/22/3/035302

PUBLISHER

(C) Institute of Physics (IOP) Publishing

VERSION

AM (Accepted Manuscript)

LICENCE

CC BY-NC-ND 4.0

\section{REPOSITORY RECORD}

Martin, Peter, and Steve Rothberg. 2019. "Methods for the Quantification of Pseudo-vibration Sensitivities in Laser Vibrometry". figshare. https://hdl.handle.net/2134/9646. 
This item was submitted to Loughborough's Institutional Repository (https://dspace.lboro.ac.uk/) by the author and is made available under the following Creative Commons Licence conditions.

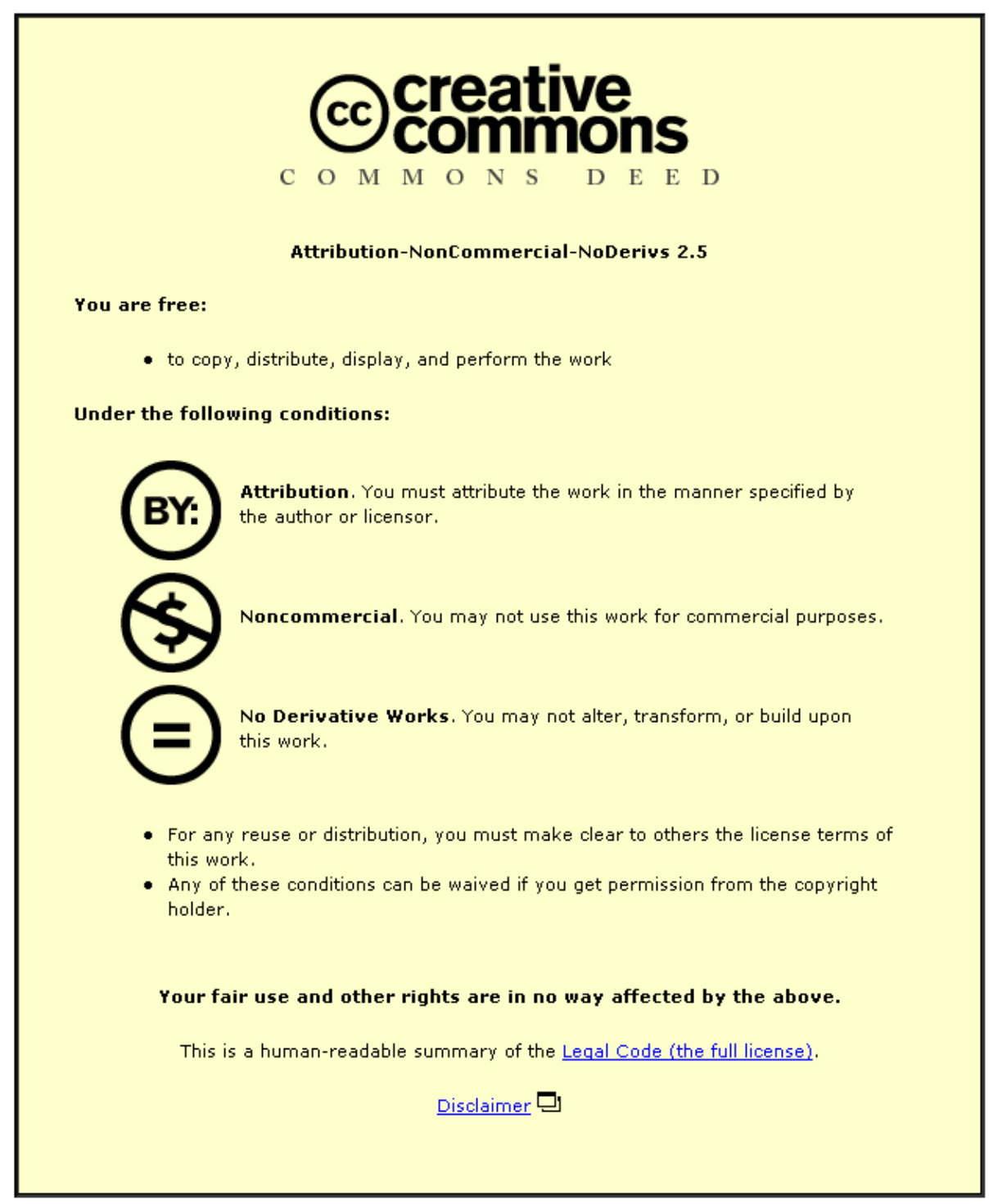

For the full text of this licence, please go to: http://creativecommons.org/licenses/by-nc-nd/2.5/ 
Methods for the Quantification of Pseudo-Vibration Sensitivities in Laser Vibrometry

(Pseudo-Vibration Sensitivities in Laser Vibrometry)

P. Martin and S. J. Rothberg

Wolfson School of Mechanical and Manufacturing Engineering

Loughborough University, Loughborough, Leicestershire, LE11 3TU, U.K.

e-mail: s.j.jothberg@ @lboro.ac.uk, tel: +44 (0) 1509 227524, fax: +44 (0) 1509227502 


\title{
Methods for the Quantification of Pseudo-Vibration Sensitivities in Laser Vibrometry
}

\author{
Peter Martin and Steve J. Rothberg \\ Wolfson School of Mechanical and Manufacturing Engineering, Loughborough \\ University, Loughborough, Leicestershire, LE11 3TU, UK.
}

e-mail: s.j.jothberg@lboro.ac.uk

\begin{abstract}
Pseudo-vibration sensitivities in laser vibrometry are the consequence of measurement noise generated by surface motions other than that on-axis with the incident laser beam(s), such as transverse and tilt vibrations or rotation. On rougher surfaces, laser speckle is the cause but similar noise is observed in measurements from smoother surfaces. This paper's principal aim is to introduce two experimental methods for quantification, including dedicated data processing, to deliver sensitivities in three forms: a spectral map, a mean level per order and a total rms level. Single and parallel beam vibrometers and different surface roughness or treatment are accommodated, with sensitivities presented for two commercial instruments (beam diameters $90 \mu \mathrm{m}$ and $520 \mu \mathrm{m}$ ). For transverse sensitivity, a total rms level around $0.05 \%$ is found for the larger beam, a quarter of the level for the smaller beam. For tilt sensitivity, advantage shifts to the smaller beam with a total rms level around $0.45 \mu \mathrm{m} / \mathrm{s} / \mathrm{deg} / \mathrm{s}$, less than one-third of that for the larger beam. Levels hold fairly constant across the rougher surfaces, reducing only for a polished surface. For rotation sensitivities (radial vibrations), advantage remains with the smaller beam with a total rms level around $2 \mu \mathrm{m} / \mathrm{s} / \mathrm{deg} / \mathrm{s}$, compared to $5 \mu \mathrm{m} / \mathrm{s} / \mathrm{deg} / \mathrm{s}$ for the larger beam, while sensitivity reduces with diminishing roughness. These sensitivities are especially valuable to vibrometer users in instrumentation selection and data analysis.
\end{abstract}

KEYWORDS: laser Doppler vibrometry, laser speckle, vibration measurement, pseudovibration, transverse sensitivity.

PACS: 06.20.-f 07.10.-h 42.30.Ms 42.79.Qx 46.40.-f 


\section{Introduction}

Laser Doppler vibrometry (LDV) is now well established as an effective, non-contact alternative to the use of a traditional contacting vibration transducer such as the accelerometer. Laser vibrometers are technically well suited to general application but offer special benefits where certain measurement constraints are imposed, for example by the context, which may demand high frequency operation, high spatial resolution or remote transducer operation, or by the structure itself, which may be hot, light or rotating.

The technique relies on the detection of a Doppler shift in the frequency of light scattered from a moving surface. In many practical cases, the coherent laser beam scatters from a surface that is rough on the scale of the optical wavelength with a lateral scale to its roughness that is smaller than the size of the beam. In such circumstances, a random distribution of high and low intensity, known as a speckle pattern, is observed in the backscattered light [1]. The photodetector in the laser vibrometer samples a portion of the speckle pattern in which the phases of the individual speckles are randomly distributed in the range -pi to pi. The amplitude and phase of the photodetector output therefore result from a phasor summation with implications for signal amplitude and measurement noise. Any particular phasor summation can result in an inadequate photodetector signal amplitude, known as 'dropout', and this is a longstanding challenge [2,3] that remains of current interest both in LDV [4] and in related, emerging techniques [5,6]. During set-up, this problem may be remedied by minor adjustment of the position of the incident laser beam but, during measurements, even very small surface motions can induce sufficient changes in the sampled speckle pattern to cause dropouts which appear as spikes in the instrument output. Dropout is exacerbated when surface reflectivity is low. In preparing for measurements, care should be taken over points of incidence to minimise dropout but occasional problems are virtually unavoidable. For the measurements presented in this paper, dropout is not a dominant source of measurement noise. Even when adequate signal amplitude is maintained, however, dynamic changes in the sampled speckle pattern cause noise in the photodetector output phase which results in 'speckle noise' in the vibrometer output signal. Its precise origins have been explained previously together with introduction of the more general term 'pseudo-vibration' $[7,8]$.

Pseudo-vibration is known to originate from motions of optically rough surfaces other than the 'onaxis' motion (i.e. that directly along the line of the incident laser beam) and, especially in recent times, its importance has been increasingly recognised [9-14]. The motions generally of greatest interest have been classified as transverse (translational oscillation perpendicular to the laser beam direction), tilt (angular oscillation around an axis perpendicular to the laser beam direction) and rotation (continuous angular motion around an axis perpendicular to the laser beam direction). Users of accelerometers, for example, will be familiar with the term 'transverse sensitivity' which is 
enshrined in ISO 16063-31 [15] and the equivalent terminology is adopted and used in this paper. Collectively, the sensitivities to all the motion types are referred to as the 'pseudo-vibration sensitivities'.

The speckle motions contribute random noise to the vibrometer output which becomes pseudorandom when target motions are periodic, as is often the case in a vibration study. This means that, when speckle noise is generated in a measurement from an optically rough surface vibrating sinusoidally, pseudo-vibration peaks will appear not only at this frequency but also at many harmonics of it, as shown in figure 1 . While the peaks due to pseudo-vibration are generally at a low level relative to the genuine on-axis motion, this still introduces some significant challenges in the interpretation of measured data, especially at harmonics where similar levels of genuine motion and pseudo-vibration may be combined [7,16]. In particular, the figure shows how amplitudes are maintained across many orders and how the highest levels are not necessarily found at the low orders. To resolve this uncertainty, it is essential for expected levels of pseudo-vibration to be quantified in a format that can be widely applied by the user. Evidence of the demand for this data comes both from attempts to quantify measured speckle noise and thus identify genuine motions in specific applications [17-19] and from recent efforts to model speckle noise [8, 20-22]. The purpose of this paper is to introduce and validate two alternative methods to enable pseudo-vibration quantification. In the processing of achieving this, initial data that is valuable in its own right has been generated, quantifying the pseudo-vibration sensitivities of two commercial laser vibrometers, and this is also presented.

The particular challenges associated with this task are to develop test rigs exhibiting only the required motions and negligible 'other' motions, to distinguish genuine motions from pseudo-vibrations within the measurements performed and to process measured data in such a way that the calculated pseudovibration sensitivities can be applied quantitatively to a diverse range of measurement applications. In addition, the experimental methods must accommodate both single beam laser vibrometers, which measure all translational vibrations [23], and parallel beam laser vibrometers, which measure all angular vibrations [24].

A further challenge is to examine and quantify how the pseudo-vibration sensitivities are affected by surface roughness or surface treatment. Many surfaces of engineering interest have a roughness comparable with the wavelength of the light which results in the formation of a so-called 'fully developed' speckle pattern [25]. At lower surface roughness (in the range of a few hundred nanometres), an increasingly apparent specular reflection is observed together with a speckle pattern that is only partially developed. In the range of a few tens of nanometres, only a specular reflection is 
apparent. Retro-reflective tape is commonly used in laser vibrometer measurements to maximise the return light intensity. In the experiments reported here, 3M Scotchlite High Gain Reflective Sheeting 7610 was used. The surface of the tape is coated with glass beads and scatter from retro-reflective tape also results in the formation of a speckle pattern. In all these cases, changes in the light collected through the vibrometer aperture result in output noise and the effect of surface roughness and surface treatment will also be part of the study presented in this paper.

This paper builds on initial work [26] which reported the introduction of what the authors then called 'speckle noise maps'. These maps showed the spectral shape of the pseudo-vibration sensitivities with an emphasis on measurements taken from rough surfaces generating speckle patterns and, hence, speckle noise. Arranging for measurements to be taken from smooth surfaces has been recognised as a route to avoid speckle noise, especially in rotor applications [27, 28], but it is now apparent that noise is still present in such measurements as a consequence of changes in the precise region of the illuminating beam from which the dominant portion of the collected light originates. For such cases, reference to 'speckle noise' is inappropriate and so the authors have adapted the more general description 'pseudo-vibration' to cover noise generated from surfaces of any roughness and with any treatment i.e. including, but not limited to, speckle noise.

In this paper, two laser vibrometers are used. The Polytec OFV302 (velocity decoder OVD01) has a beam diameter of $90 \mu \mathrm{m}$ and is positioned at the recommended stand-off distance of $600 \mathrm{~mm}$. The Polytec OFV400 has a beam diameter of $520 \mu \mathrm{m}$ and is positioned at the recommended stand-off distance of $400 \mathrm{~mm}$. The beams are focussed at these distances. In all experiments, range settings were adjusted to suit signal levels. The OFV400 is a parallel beam laser vibrometer which can also be used as a single beam vibrometer using a simple cap placed over the aperture to block one beam. This instrument is used both as a single beam vibrometer for translational vibration measurements and as a parallel beam vibrometer for angular vibration measurements in the tests reported in this paper.

For all measurements in this study, it is vital to reduce all but the single motion component under test to the lowest possible levels. This is achieved through the design of dedicated test rigs and through appropriate alignment of the laser beam(s) relative to the surface motion, resulting in vibrometer measurements dominated by noise. It is not necessary to measure these minimised motion components with the important exception of the genuine, on-axis component of surface velocity for which compensation must be made. Both methods described in this paper require three simultaneous measurements.

\section{Quantification of Pseudo-Vibration Sensitivity: Method based on correction for residual,}




\section{genuine velocity}

Quantification of transverse and tilt sensitivities exemplifies use of this first method. The first of the three measurements might be regarded as the intended measurement; it is the one that is dominated by pseudo-vibration (as a result of the rig design and laser beam alignment) but which will inevitably contain some residual, genuine on-axis velocity. This is referred to as the 'measured velocity', $U_{\text {meas }}$. The second measurement is intended to isolate the component of genuine velocity, $U_{g e n}$, in the first measurement. Subtraction provides the best estimate of pseudo-vibration, termed the 'apparent velocity', $U_{a p p}$, and written as:

$U_{\text {app }}=U_{\text {meas }}-U_{\text {gen }}$

The third measurement provides the transverse or tilt velocity itself and its use for normalisation is explained in section 2.3 .

\subsection{Periodic transverse motion: experimental arrangement}

The test surface has a translational vibration in a direction which defines the $z$-axis and is perpendicular to the optical axis of the laser beam, as shown in figure 2. The test surface is fixed to a carriage which is attached to a high precision linear rail. A linear shaker excites the carriage through a stinger. The stinger is axially aligned with the centre of gravity of the carriage assembly to minimise eccentric forces. In this way, $x$-, $y$ - and $z$-components of angular vibration velocity, and $x$ - and $y$ components of translational vibration velocity are considered minimised.

The shaker drives a sinusoidal $z$-vibration of the carriage and test surface, measured by an accelerometer. (While the desire was to generate a pure sinusoidal vibration, some harmonic distortion was evident and fundamental components were typically $40 \mathrm{~dB}$ higher than the largest harmonics seen in the tilt and transverse motion experiments). Laser beam A provides the measured velocity. This beam must be aligned in the $x$-direction, where the $x z$ plane is horizontal. This alignment is critical otherwise components of the $z$-velocity are measured in proportion to the sine of the angle $\beta$ shown in the figure. Genuine $x$-components of velocity remain and so laser beam $\mathrm{B}$, incident on a mirror attached adjacent to the test surface, measures the genuine $x$-velocity with minimal noise. For convenience, laser beam B is directed to the surface via a beamsplitter.

For appropriate cancellation of genuine velocity between these two measurements, beams A and B must both be aligned in the $x$-direction. This is achieved by making both beams incident on a mirror clamped to the front of the test surface. Angular adjustments are then made to minimise the $z$ component of translational vibration velocity in each measurement. When this is achieved, the mirror 
is repositioned, exposing the test surface to beam A but leaving beam B incident on the mirror surface.

\subsection{Periodic tilt surface motion: experimental arrangement}

The test surface has an angular vibration around an axis which defines the $z$-direction and is perpendicular to the optical axis of the laser beam as shown in figure 3 . The test surface is fixed to a carriage which rotates in bearings fixed in a heavy pedestal (not shown). The point of incidence of the beam sits directly on the rotation axis of the carriage and, in this way, $x$ - and $y$-components of angular vibration velocity and $x$-, $y$ - and $z$-components of translational vibration velocity are considered minimised.

A linear shaker drives the required $z$-component of angular vibration through a lever arm. This component is measured using an accelerometer fixed at a known radial distance from the axis of rotation. The incident laser beam provides the measured velocity. This beam must be aligned in the $x$ direction, where the $x z$ plane is horizontal, and this is achieved by mounting a mirror surface on the carriage while it is stationary and using the reflection of the beam to minimise the angle $\beta$. Genuine $x$ components of velocity remain and so a measurement of the genuine $x$-velocity is taken from the bearing housing using a second vibrometer aligned in the $x$-direction and in the same plane as the rotation axis. For appropriate cancellation of genuine velocity between these two measurements, it is critical to minimise the offset of the measured velocity beam from the rotation axis, shown as $\mathrm{y}_{0}$ in the figure. A micro-positioning device, attached to the vibrometer, is used to achieve this by minimising the measured velocity due to the $z$-component of angular velocity which is directly proportional to this offset.

\subsection{Processing the apparent velocity}

In measurements from optically rough surfaces, the apparent velocity is dominated by speckle noise and its spectrum takes the form shown previously in figure 1. The figure emphasises the broadband characteristics of speckle noise, with amplitudes maintained across the 80 harmonics shown. Even in measurements from smoother surfaces, apparent velocity takes this same form.

To estimate pseudo-vibration sensitivity, the amplitudes of each harmonic in the apparent velocity

spectrum, $\widehat{U}_{a p p, N}$ for orders $N=1$ to 50, are found. Correction for the picket fence effect [29] was made to these amplitudes. (Picket fence effect can, of course, be avoided by synchronising excitation frequency with acquisition parameters but, while preferable, this was not possible in the set-up used for these tests). Vibration frequency affects noise levels linearly; for example, increasing vibration frequency results in the phase changes causing noise simply happening more quickly. To remove the 
effect of vibration frequency, the apparent velocity is normalised by the velocity amplitude, at the fundamental frequency, of the motion causing pseudo-vibration, $\widehat{U}$. This process is verified in figure 4 which shows tilt sensitivity for a surface with roughness $\mathrm{Ra} 0.19 \mu \mathrm{m}$ and angular vibration at frequencies 10, 20 and $30 \mathrm{~Hz}$. The tilt sensitivity map for each vibration frequency was created from multiple (in this case and elsewhere in this paper 10) spectra from measurements at different locations on a test surface from which uncorrelated speckle patterns are formed. Pseudo-vibration sensitivity at each order $N, S_{P V, N}$, is therefore written as a mean value as follows:

$S_{P V, N}=\frac{1}{M} \sum_{m=1}^{M}\left[\frac{\widehat{U}_{a p p, N}}{\widehat{U}}\right]_{m}$

while the corresponding (sample) standard deviation, $\sigma_{P V, N}$, is written:

$\sigma_{P V, N}=\sqrt{\frac{1}{M-1} \sum_{m=1}^{M}\left(\left[\frac{\widehat{U}_{a p p, N}}{\widehat{U}}\right]_{m}-S_{P V, N}\right)^{2}}$

where $M$ is the number of individual spectra from distinct locations contributing to these calculations. The mean and standard deviation at each of the 50 orders are calculated. There are no significant differences between the normalised levels for each vibration frequency which means that, with this normalisation, pseudo-vibration sensitivity is independent of vibration frequency and suitable as general quantitative guidance to a user. (Note that normalisation does result in a baseline noise level that decreases with increasing vibration frequency because use of constant displacement amplitude means normalisation by an increasing velocity amplitude). Such maps are used for presentation of all pseudo-vibration sensitivities.

In addition to these maps, pseudo-vibration sensitivities are also expressed in two simple, quantitative formats. The first is a mean level per order calculated from order N1 up to N2 (usually orders 1 to 10), $\overline{S_{P V, N 1 \rightarrow N 2}}$, with a corresponding (sample) standard deviation, $\sigma_{P V, N 1 \rightarrow N 2}$, written as:

$$
\begin{aligned}
& \overline{S_{P V, N 1 \rightarrow N 2}}=\frac{1}{N 2-N 1+1} \sum_{N=N 1}^{N 2} S_{P V, N} \\
& \sigma_{P V, N 1 \rightarrow N 2}=\sqrt{\frac{1}{N 2-N 1} \sum_{N=N 1}^{N 2}\left(S_{P V, N}-\overline{S_{P V, N 1 \rightarrow N 2}}\right)^{2}}
\end{aligned}
$$


A bandwidth of 10 orders is chosen as a typical bandwidth over which the vibrometer user is likely to be interested. The second format is the total rms value, $\left[S_{P V, N 1 \rightarrow N 2}\right]_{R M S}$, again usually calculated from orders 1-10, and written as:

$\left[S_{P V, N 1 \rightarrow N 2}\right]_{R M S}=\sqrt{\sum_{N=N 1}^{N 2} \frac{\left(S_{P V, N}\right)^{2}}{2}}$

Equations (3a\&b) and (4) present formats allowing easier comparison, for example between instruments. They differ from those found in ISO 16063-31 as a direct consequence of the way in which a sinusoidal target motion results in measurement noise at many harmonics of the fundamental frequency in LDV. Mean level per order would assist the user observing data in the frequency domain while total rms might be more appropriate when observing data in the time domain. The latter can be readily scaled for different bandwidths because the spectral shape of the pseudo-vibration across a reasonable bandwidth is usually quite flat. These formats are used for quantification of all pseudovibration sensitivities.

\subsection{Quantification of transverse sensitivity}

The test surfaces were vibrating at $60 \mathrm{~Hz}$ with a displacement of $420 \mu \mathrm{m} \mathrm{rms}$. The significance of this displacement was that it corresponded to a translation of at least one whole beam diameter for the larger beam. This guarantees decorrelation of the speckle pattern incident on the collecting aperture of the laser vibrometer in measurements from rough surfaces.

Figure 5a shows typical measured velocity, figure $5 \mathrm{~b}$ shows the corresponding genuine velocity measurement and figure $5 \mathrm{c}$ shows the apparent velocity, from equation (1). In each case, the transverse velocity is also shown for reference. The magnitude of genuine velocity is approximately $60 \mathrm{~dB}$ down on that of the transverse velocity but the similarity between measured and genuine velocities emphasises the importance of correcting for genuine velocity. The resulting apparent velocity in Figure 5c shows very clearly how the sinusoidal transverse motion of the surface causes speckle noise to appear to reflect and negate around the instances in time when the surface is stationary. The more prominent peaks of speckle noise occur in the temporal vicinity of maximum surface velocity which is typical of speckle noise because the rate of changes in the speckle pattern is directly proportional to the surface velocity.

Tests were performed for surfaces with Ra roughness of $11 \mathrm{~nm}, 75 \mathrm{~nm}$ and $1 \mu \mathrm{m}$ and for a surface treated with retro-reflective tape. The transverse sensitivity maps (standard deviations omitted for clarity) are shown in figures $6 \mathrm{a} \& \mathrm{~b}$ for incident beam diameters of $520 \mu \mathrm{m}$ and $90 \mu \mathrm{m}$ respectively. 
Table 1 summarises the transverse sensitivities and shows typical speckle pattern images covering the transition from fully developed to partially developed speckle patterns and then to simple specular reflection with diminishing surface roughness.

Transverse sensitivity takes a mean level of approximately $0.01 \%$ to $0.03 \%$ per order, based on the first 10 orders, for the beam diameters of $520 \mu \mathrm{m}$ and $90 \mu \mathrm{m}$ respectively. The standard deviation in the amplitude of the orders is around two-thirds of the mean. The total rms level over orders 1-10 is around $0.05 \%$ for a $520 \mu \mathrm{m}$ beam diameter and slightly less than $0.2 \%$ for a $90 \mu \mathrm{m}$ beam diameter. This corresponds to an advantage through use of the larger beam by a factor of around 3 to 4 .

In general, the surface roughness appears to make little difference to sensitivities except for the smoothest surface ( $\mathrm{Ra} 11 \mathrm{~nm}$ ) with the $90 \mu \mathrm{m}$ beam diameter where transverse sensitivity is 3 to 4 times lower than for other surfaces with this smaller beam. This conclusion is confirmed by further analysis for statistical significance in the differences between the mean values. Transverse sensitivities for the Ra $75 \mathrm{~nm}$ surface, which produces partially developed speckle patterns, appear to be comparable with sensitivities from the rougher surfaces (Ra $1 \mu \mathrm{m}$ and the surface coated with retroreflective tape) which produce fully developed speckle patterns. This suggests the underlying, partially developed speckle pattern is a significant component in the collected light from which the measurement is taken. For the larger beam, transverse sensitivity reduces with order much more noticeably than for the smaller beam. While the broader spectral content of pseudo-vibration must be borne in mind, the vibrometer transverse sensitivities compare very favourably at a few tenths of a percent to values of a few percent typical, for example, with piezo-electric accelerometers.

\subsection{Quantification of tilt sensitivity}

For surface angular motion, speckles are expected to translate predominantly. In these tests, an angular displacement of $0.78^{\circ} \mathrm{rms}$ (at $60 \mathrm{~Hz}$ ) was chosen such that the resulting speckle translation distances of $45 \mathrm{~mm}$ and 30mm, at the recommended stand-off distances, exceeded each vibrometer receiving aperture dimension. Figure 7 shows a typical plot of apparent velocity together with the angular velocity of the surface. Speckle noise again appears to reflect and negate around the instances in time when the surface is stationary. The more prominent peaks of speckle noise again occur in the temporal vicinity of maximum surface velocity as seen in figure $5 \mathrm{c}$ for transverse motion. Data such as those presented in Figure 7 were captured for each test and processed according to section 2.3. Tilt sensitivity maps (units of $\mu \mathrm{m} / \mathrm{s} / \mathrm{deg} / \mathrm{s}$ ) are shown in figures $8 \mathrm{a} \& \mathrm{~b}$ for beam diameters of $520 \mu \mathrm{m}$ and $90 \mu \mathrm{m}$ respectively. The smaller beam significantly reduces tilt sensitivity, particularly at higher order harmonics. For the rougher surfaces producing speckle patterns, this occurs because the smaller diameter increases the size of the speckle and larger speckles result in slower phase variations in the 
Doppler signal. However, figures $8 \mathrm{a} \& \mathrm{~b}$ also show how little surface treatment or roughness affects the tilt sensitivity. Tilt sensitivity from the smoothest surface, which produces only specular reflections, is similar to those from the rougher surfaces.

These similarities are reinforced in table 2 (speckle pattern images would be similar to those in table 1 and so are not repeated) in which tilt sensitivity is quantified at a mean level by order, over the first ten orders, of approximately $0.25 \mu \mathrm{m} / \mathrm{s} / \mathrm{deg} / \mathrm{s}$ or $0.075 \mu \mathrm{m} / \mathrm{s} / \mathrm{deg} / \mathrm{s}$ for beam diameters of $520 \mu \mathrm{m}$ and $90 \mu \mathrm{m}$ respectively. The total $\mathrm{rms}$ level over orders $1-10$ is about $1.2 \mu \mathrm{m} / \mathrm{s} / \mathrm{deg} / \mathrm{s}$ for a $520 \mu \mathrm{m}$ beam diameter and $0.45 \mu \mathrm{m} / \mathrm{s} / \mathrm{deg} / \mathrm{s}$ for a $90 \mu \mathrm{m}$ beam diameter. Further analysis shows that there are no statistically significant differences within each set of values but it is clear that use of the smaller beam reduces tilt sensitivity by a factor of around 3 to 4 .

\section{Quantification of Pseudo-Vibration Sensitivity: Method based on a differential measurement}

This second method is based on a differential measurement using two identical instruments. An apparent velocity is calculated from the difference between two, very closely spaced, simultaneous measurements on the test structure. The principle applied is that these measurements will have common vibration content but differential noise content by virtue of the beams illuminating distinct (separation comparable with beam diameter) regions on the test structure. The advantage of this approach is that it can be used when it is difficult to obtain a reliable measurement of genuine velocity to use for correction of the measured velocity to form the apparent velocity. The obvious disadvantage is the requirement for two instruments and there is an implicit, although reasonable, assumption of similar performance for each instrument. Validation of this approach is given in the next sub-sections where pseudo-vibration sensitivity is quantified in measurements of radial vibrations and torsional vibrations on rotating shafts, with normalisation by rotation speed.

\subsection{Continuous rotation: experimental arrangement for radial vibration measurement}

In these tests, the $z$-axis is defined by the rotation axis of the shaft. A radial vibration measurement requires a single beam aligned to intersect the rotation axis of the rotor normally [23] and this defines the $x$-direction as shown by beam $\mathrm{A}$ in figure 9 . This measurement will be sensitive to velocity components in the direction of the beam, prone to speckle noise (for rougher surfaces) and sensitive to shaft out-of-roundness (on smoother surfaces). For surfaces generating fully developed speckle patterns (e.g. Ra $1 \mu \mathrm{m}$ and the surface treated with retro-reflective tape), there is proven insensitivity to shaft out-of-roundness [23].

The rig carries a mirror whose normal is in the $x$-direction. The mirror is used to make beams A and $\mathrm{B}$ parallel with each other and with the $x$-axis. Fine angular adjustments are made using a precision 
tripod head. Each beam $y$-position is then adjusted (without affecting angular alignment) so that it is roughly aligned through the rotation axis; this is followed by a fine alignment using a precision tripod head until the DC component of measured velocity is minimised. This means that each beam is aligned to pass through the rotation axis. Assisted by a Dove Prism, as shown in the figure, the beams are positioned as close to each other as is practically possible with no overlap. The rotor runs in bearings mounted in a heavy pedestal and is driven through a flexible belt by a DC motor. In this way, all components of angular and translational vibration velocity are considered minimised. The test shafts have $15 \mathrm{~mm}$ diameters, rotate at $35 \mathrm{~Hz}$ and have a range of surface roughness values from 11 $\mathrm{nm}$ to $1 \mu \mathrm{m}$.

\subsection{Processing the apparent velocity}

Figure 10 shows an initial consideration of rotation sensitivities. The triangular markers show the sensitivity calculated from a single measurement (no correction for genuine velocity) on a smooth surface $(\mathrm{Ra} 11 \mathrm{~nm})$. This measurement ought to show any genuine velocity and shaft out-of-roundness but no speckle noise. The circular markers show the sensitivity calculated from a measurement at an adjacent location on the shaft that had been covered with retro-reflective tape. This measurement should show the same sensitivity to genuine velocity, a sensitivity to speckle noise but no dependence on shaft out-of-roundness. The diamond markers use the new method based on a differential measurement to give a refined estimate of rotation sensitivity. This quantity should show minimal sensitivity to genuine velocity and shaft out-of-roundness, which is cancelled in forming the difference, leaving only uncorrelated noise between the two measurements. Since the measurements on which this calculation is based are taken from a shaft with Ra $11 \mathrm{~nm}$, any such noise should be very low level. The measurement from retro-reflective tape shows the familiar, flat spectral shape of speckle noise with little hint of any genuine velocity in the measurement. This strongly suggests that the raised sensitivities at low orders in the single measurement from the smooth surface are due principally to shaft out-of-roundness. Furthermore, the spectral shape of this map, compared to the refined estimate, suggests that the influence of shaft out-of-roundness is apparent up to around the $20^{\text {th }}$ rotation order. The differential measurement still shows some suggestion of sensitivity to out-ofroundness at the first order and a hint at the next few orders but the levels are considerably reduced. The challenge with this approach is in the ability to make the two adjacent measurements identical in terms of genuine velocity, out-of-roundness and alignment. The resulting pseudo-vibration estimate is much improved in the view of the authors. Note that it is not the intention to include shaft out-ofroundness under the description 'pseudo-vibration'. This is a separate issue in need of further investigation but outside the scope of this particular study. 
Returning to figure 9, if the difference between these two measurements is dominated by the uncorrelated noise in each measurement then the rms of this difference ought to be $\sqrt{2}$ of either of the individual (near identical) rms levels. This notion is supported by figures 11a-c which show the individual measurements, $U_{\text {meas }, A}$ and $U_{\text {meas }, B}$, with very similar rms, and their difference with the expected rms level. In each plot, including the difference plot, distinctive peaks have been circled to emphasise the periodicity of speckle noise. For this method, the required apparent velocity is therefore written:

$U_{\text {app }}=\left(U_{\text {meas }, A}-U_{\text {meas }, B}\right) / \sqrt{2}$

Calculation of rotation sensitivity based on this approach then proceeds according to section 2.3.

Figure 12 shows rotation sensitivity (from a surface coated in retro-reflective tape) based on a single measurement (without correction so reliant on minimal genuine velocity and known insensitivity to shaft-out-of-roundness) alongside that based on the differential measurement which would be a robust estimate even if the individual measurements were affected by genuine velocity (possible in all measurements) and shaft out-of-roundness (in measurements on smoother surfaces). Close agreement is found and figures 11 and 12 are offered as confirmation of the validity of this method based on a differential measurement.

\subsection{Quantification of Rotation Sensitivity (radial vibration measurements)}

Figures $13 \mathrm{a} \& \mathrm{~b}$ show the rotation sensitivity maps for incident beam diameters of $520 \mu \mathrm{m}$ and $90 \mu \mathrm{m}$ respectively. Table 3 presents the rotation sensitivities in the usual formats together with typical images of collected light. Compared to the images shown in table 1, there are detail differences relating mainly to illumination of different surfaces but also to differences in Ra value. The main distinction, however, is in the overall intensity profiles which show the influence of shaft curvature.

Considering the mean levels per order, based on the first ten orders, it is notable that for both beams the surface with $\mathrm{Ra} 65 \mathrm{~nm}$ has resulted in higher sensitivities than in the measurements on rougher surfaces. Generally, rotation sensitivity is not expected to increase as surfaces become smoother and correlation times increase in the backscattered light due to the diminishing influence of speckle, as indicated by the images of scattered light patterns shown in the table. Sourcing the tests shafts with their different roughness values was difficult and it was not possible to maintain control simultaneously over out-of-roundness which happened to be larger for this shaft than for others (27 $\mu \mathrm{m}$ compared to others in the range of 1-7 $\mu \mathrm{m}$ ). This potential problem was also suggested in figure 10 where residual sensitivity to out-of-roundness was observed in the differential measurement. It is also notable that, in comparison to the transverse and tilt sensitivities, the standard deviations are large 
relative to the means, typical of datasets in which a small number of large values dominate. An additional reason for this may be the influence of genuine radial vibrations generated as a result of the need to rotate the shaft for the tests and not completely cancelled in the differential measurements due to small but inevitable misalignment between the two beams.

Recognising the relatively flat spectral shape of the rotation sensitivity maps, the authors propose the use of higher orders for the quantification of rotation sensitivity so table 3 also shows mean levels per order based on orders 11-20, 21-30 and 41-50. It was shown earlier how measurable out-of-roundness components may prevail up to $20^{\text {th }}$ order in an individual measurement and how low orders may still be prominent in the differential measurement. The task is to find an order range that strikes the right compromise to provide an estimate of pseudo-vibration in orders 1-10; too low a range and there will be sensitivity to out of roundness and genuine velocity, too high a range and the levels at orders 1-10 will be underestimated as demonstrated by the general trend of reducing mean levels with increasing order range shown in table 3. Based on orders 11-20, for both beams, the expected trend in the standard deviation has been restored but the measurements on the $65 \mathrm{~nm}$ surface are still showing unexpectedly high levels relative to the rougher surfaces. Across orders 21-30, the levels for the rougher shafts remain at similar levels but the level for the $65 \mathrm{~nm}$ surface is much reduced and the expected trend of reducing sensitivity with diminishing roughness is now apparent. By orders 41-50, levels have started to fall noticeably. Orders 21-30 are, therefore, chosen as the range on which to base the quantification of rotation sensitivities.

Considering the mean levels per order, based on orders 21-30, the advantage of a smaller beam, as in the case of the tilting surface, is clear. Smaller diameter means a larger speckle size, which increases the correlation time associated with translating speckle and in turn reduces the rotation sensitivity. For the $520 \mu \mathrm{m}$ beam, the rotation sensitivity is of the order of $1.5 \mu \mathrm{m} / \mathrm{s} / \mathrm{rad} / \mathrm{s}$ for the rougher surfaces reducing to half this level for the Ra $65 \mathrm{~nm}$ surface and then to slightly below $0.2 \mu \mathrm{m} / \mathrm{s} / \mathrm{rad} / \mathrm{s}$ for the Ra $11 \mathrm{~nm}$ surface. The standard deviations vary between around 0.45 and 0.7 of the mean. Further statistical analysis shows that the mean levels for the surface coated in retro-reflective tape and the Ra $1.0 \mu \mathrm{m}$ surface are not significantly different, nor are the mean levels for the Ra $270 \mathrm{~nm}$ and the Ra 65 nm surfaces. Statistically significant differences are found for all other combinations i.e. between those with highest roughness, those with intermediate roughness and the polished surface. The surface coated with retro-reflective tape produces the highest rotation sensitivities of all the surfaces.

For the $90 \mu \mathrm{m}$ beam, the rotation sensitivities are around a half of those for the larger beam for the rougher surfaces and about three-quarters of those for the smoother surfaces. The measurement on the surface coated with retro-reflective tape has only one-third of the sensitivity encountered with the 
larger beam. Standard deviations are around a half of the corresponding mean values. Further statistical analysis shows that the mean levels for the Ra $1.0 \mu \mathrm{m}$ and $\mathrm{Ra} 270 \mathrm{~nm}$ surfaces, which are the highest, are not significantly different, nor are the mean levels for the surface coated in retroreflective tape and the Ra $65 \mathrm{~nm}$ surface. The similarity between the sensitivities for the surface coated in retro-reflective tape and the Ra $65 \mathrm{~nm}$ surface is notable and likely to be related to the absence of a fully-developed speckle pattern when the light scatters from the glass beads on the tape surface, as shown in table 3. Statistically significant differences are found for all other combinations.

\subsection{Quantification of Rotation Sensitivity (torsional vibration measurements)}

Parallel beam laser vibrometers enable measurement of angular vibrations on both rotating and nonrotating targets. In this section, rotation sensitivity is evaluated for the classic torsional vibration measurement in which the parallel beams are incident on a rotating shaft in a plane that is perpendicular to the shaft rotation axis [24] as shown in figure 14 . These tests use the same rig and alignment procedure as for section 3.1 with the exception that the beams in each pair are positioned approximately equidistant from the rotation axis and the additional requirement that the beams in each pair occupy a plane whose normal is orientated in the $z$-direction. All components of angular and translational vibration velocity are considered minimised by the rig design but, in addition, the parallel beam configuration fundamentally offers immunity to translational velocities and the chosen alignment ensures sensitivity to any residual pitch and yaw vibration is minimised [24]. The beam pairs are positioned as close to each other as is practically possible with no overlap. Figure 14 shows the two closely spaced measurements from which the differential measurement is obtained. The shaft tested was treated with retro-reflective tape and was rotating at $30 \mathrm{~Hz}$. When untreated, surface orientation at the points of laser beam incidence tends to reflects the beam away from the receiving aperture of the vibrometer and, in these tests, reliable measurements were not possible from untreated surfaces. Normalisation by rotation speed produces rotation sensitivity in units of deg/s / rad/s.

Figure 15 shows the rotation sensitivity map with its flat spectral shape. This map also shows standard deviation at each order. In the maps previously shown, standard deviations were omitted for clarity because of the presentation of multiple data series but they are a valuable additional piece of information. In this case, rotation sensitivity could be based on the first ten orders, rather than orders 21-30, because of the insensitivity to out-of-roundness associated with the use of retro-reflective tape but there may be residual sensitivity to genuine velocity (generated as a result of the need to rotate the shaft for the tests) that is not completely cancelled in the differential measurements due to small but inevitable misalignment between the two beam pairs. Maintaining the principle established earlier, orders 21-30 are used for the quantification giving a mean level per order of $21.5 \mathrm{mdeg} / \mathrm{s} / \mathrm{rad} / \mathrm{s}$, with standard deviation $10.0 \mathrm{mdeg} / \mathrm{s} / \mathrm{rad} / \mathrm{s}$, and total $\mathrm{rms}$ of $68.7 \mathrm{mdeg} / \mathrm{s} / \mathrm{rad} / \mathrm{s}$. 


\section{Further Work}

The work presented in this paper has concentrated on vibration and rotation frequencies in the range of several tens of $\mathrm{Hz}$, up to a maximum of $60 \mathrm{~Hz}$. Based on consideration of the noise generating mechanism [8], it is reasonable to assume that the calculated rotation sensitivities can be applied to rotation at any speed and that transverse and tilt sensitivities can be applied to vibration at any frequency provided that the target displacement amplitude is at least sufficient for the speckle pattern collected through the vibrometer aperture to decorrelate during the vibration cycle. This condition should include the large beam displacements associated with the continuous scanning LDV technique [30, 31] for which a recent study reported insensitivity to scan length [32]. The tilt and transverse sensitivities calculated here cannot, however, be used so reliably for smaller target displacements that are insufficient to cause decorrelation of the collected speckle pattern. In particular, this will apply at higher vibration frequencies where vibration displacements are naturally smaller. The principal focus of this paper is on the methods for quantification and these are perfectly suited to examination of the effect of reducing vibration displacements which will be part of a follow-up study. Initial experimentation suggests an increase in the mean level per order, across orders 1 to 10 , by a factor of slightly less than 2 for an eight-fold reduction in vibration amplitude. In addition, the pseudovibration maps become less flat with decreasing vibration amplitude, rolling off with increasing order. Similar ratios of displacement amplitude to beam diameter (using different instruments) produce similar spectral shapes but not necessarily similar sensitivities. The authors believe that the methods presented are suitable for development in a Standard and this will be a focus of future work in which consideration of displacement amplitudes must feature.

Further work should also investigate surface motions other than sinusoidal. This might include whole body translations at constant [33] or near-constant velocity [34] and random surface vibrations where measurement noise would not have the periodic form illustrated in figure 1. For torsional vibration measurements with a parallel beam laser vibrometer, small oscillatory translations of the beam pair along the shaft axis [35] and surface modification [36] have both been used in deliberate attempts to prevent the periodic repeat of measurement noise. This does not reduce total rms noise levels but it does reduce levels at the integer orders which are often of greatest interest. Such arrangements should be considered as part of any study of random surface vibrations.

\section{Conclusions}

This paper has successfully reported the development and validation of the first known methods for the quantification of pseudo-vibration sensitivities encountered in laser vibrometry. In laser vibrometer applications on optically rough surfaces, pseudo-vibration results from the dynamic 
behaviour of the speckle patterns formed by scattering from the surface. On smoother surfaces creating specular reflections, it was found that pseudo-vibrations were still apparent as a result of changes in the precise region of the illuminating beam from which the dominant portion of the collected light originated. Two methods have been presented, both requiring dedicated test rigs, careful alignment procedures and an approach to data processing and presentation that maximises the usefulness of these sensitivities to the vibrometer user. The first method requires correction of the vibrometer measurement with an independent measurement of genuine velocity to produce an apparent velocity dominated by the required noise components. The second method requires a differential measurement using two identical vibrometers to cancel common components such as genuine velocity, leaving only uncorrelated noise from each measurement in the resulting apparent velocity. In each case, a third measurement is required of the surface motion component causing pseudo-vibration and this is used to normalise the apparent velocity. Pseudo-vibration sensitivity is then presented as a map showing the spectral shape of the noise, as the mean and standard deviation of each harmonic peak in the map, and as a total rms level across a defined bandwidth.

Both methods have proved reliable and practical. For the first time, transverse, tilt and rotation sensitivities have been evaluated and these have been presented for the Polytec OFV302 and OFV400 commercial laser vibrometers as a function of surface roughness or treatment. The latter instrument has been assessed in both single beam and parallel beam modes. In addition to the detailed quantifications provided, the general advantages of use of a larger beam in the presence of transverse vibrations and a smaller beam for tilt vibrations and rotation have been demonstrated. These data are of considerable value to the vibrometer user engaged in instrumentation selection and in accurate interpretation of measured data.

\section{Acknowledgements}

The authors would like to acknowledge the support of the Engineering and Physical Sciences Research Council, who provided the PhD studentship for Peter Martin, and the Royal Commission for the Exhibition of 1851 who funded certain equipment purchase. 
Table 1. Transverse sensitivity (\%). Target displacement $420 \mu \mathrm{m}$ rms.

\begin{tabular}{|c|c|c|c|c|}
\hline Surface finish: & $\begin{array}{c}\text { Retro-reflective } \\
\text { tape }\end{array}$ & $\begin{array}{c}\mathrm{Ra} 1.0 \mu \mathrm{m} \\
\quad(1.6 \lambda)\end{array}$ & $\begin{array}{c}\mathrm{Ra} 75 \mathrm{~nm} \\
(0.12 \lambda)\end{array}$ & $\begin{array}{r}\mathrm{Ra} 11 \mathrm{~nm} \\
(0.02 \lambda)\end{array}$ \\
\hline \multicolumn{5}{|c|}{ Polytec OFV400 (single beam mode): Beam diameter $520 \mu \mathrm{m}$} \\
\hline \multicolumn{5}{|c|}{$\begin{array}{l}\text { Typical scattered } \\
\text { light patterns }\end{array}$} \\
\hline $\begin{array}{l}\text { Mean level by } \\
\text { order (standard } \\
\text { deviation), } \\
\text { orders } 1-10\end{array}$ & $\begin{array}{c}0.0112 \\
(0.00704)\end{array}$ & $\begin{array}{c}0.00768 \\
(0.00547)\end{array}$ & $\begin{array}{c}0.0107 \\
(0.00790)\end{array}$ & $\begin{array}{c}0.00895 \\
(0.00808)\end{array}$ \\
\hline $\begin{array}{l}\text { Total RMS } \\
\text { level across } \\
\text { orders } 1-10\end{array}$ & 0.0388 & 0.0255 & 0.0351 & 0.0327 \\
\hline \multicolumn{5}{|c|}{ Polytec OFV302: Beam diameter $90 \mu \mathrm{m}$} \\
\hline \multicolumn{5}{|c|}{$\begin{array}{l}\text { Typical scattered } \\
\text { light patterns }\end{array}$} \\
\hline $\begin{array}{l}\text { Mean level by } \\
\text { order (standard } \\
\text { deviation), } \\
\text { orders } 1-10\end{array}$ & $\begin{array}{c}0.0245 \\
(0.0175)\end{array}$ & $\begin{array}{c}0.0317 \\
(0.0199)\end{array}$ & $\begin{array}{c}0.0288 \\
(0.0206)\end{array}$ & $\begin{array}{c}0.00730 \\
(0.00258)\end{array}$ \\
\hline $\begin{array}{l}\text { Total RMS } \\
\text { level across } \\
\text { orders } 1-10\end{array}$ & 0.0786 & 0.103 & 0.0954 & 0.0407 \\
\hline
\end{tabular}


Table 2. Tilt sensitivity $(\mu \mathrm{m} / \mathrm{s} / \mathrm{deg} / \mathrm{s})$. Angular displacement $0.78^{\circ} \mathrm{rms}$.

\begin{tabular}{|c|c|c|c|c|}
\hline Surface finish & $\begin{array}{l}\text { Retro-reflective } \\
\text { tape }\end{array}$ & $\begin{array}{c}\mathrm{Ra} 1.0 \mu \mathrm{m} \\
(1.6 \lambda)\end{array}$ & $\begin{array}{c}\operatorname{Ra} 75 \mathrm{~nm} \\
(0.1 \lambda)\end{array}$ & $\begin{array}{c}\mathrm{Ra} 11 \mathrm{~nm} \\
(0.02 \lambda)\end{array}$ \\
\hline \multicolumn{5}{|c|}{ Polytec OFV400 (single beam mode): Beam diameter $520 \mu \mathrm{m}$} \\
\hline $\begin{array}{l}\text { Mean level by } \\
\text { order (standard } \\
\text { deviation), } \\
\text { orders } 1-10\end{array}$ & $\begin{array}{c}0.279 \\
(0.153)\end{array}$ & $\begin{array}{c}0.276 \\
(0.158)\end{array}$ & $\begin{array}{c}0.236 \\
(0.166)\end{array}$ & $\begin{array}{c}0.252 \\
(0.168)\end{array}$ \\
\hline $\begin{array}{l}\text { Total RMS } \\
\text { level across } \\
\text { orders } 1-10\end{array}$ & 0.933 & 0.961 & 0.770 & 0.832 \\
\hline \multicolumn{5}{|c|}{ Polytec OFV302: Beam diameter $90 \mu \mathrm{m}$} \\
\hline $\begin{array}{l}\text { Mean level by } \\
\text { order (standard } \\
\text { deviation), } \\
\text { orders } 1-10\end{array}$ & $\begin{array}{c}0.0572 \\
(0.0417)\end{array}$ & $\begin{array}{c}0.0783 \\
(0.0643)\end{array}$ & $\begin{array}{c}0.0732 \\
(0.0531)\end{array}$ & $\begin{array}{c}0.0970 \\
(0.0633)\end{array}$ \\
\hline $\begin{array}{l}\text { Total RMS } \\
\text { level across } \\
\text { orders } 1-10\end{array}$ & 0.219 & 0.278 & 0.239 & 0.318 \\
\hline
\end{tabular}


Table 3. Rotation sensitivity $(\mu \mathrm{m} / \mathrm{s} / \mathrm{rad} / \mathrm{s})$ in radial vibration measurement.

\begin{tabular}{|c|c|c|c|c|c|}
\hline Surface finish & $\begin{array}{l}\text { Retro-reflective } \\
\text { tape }\end{array}$ & $\begin{array}{c}\operatorname{Ra} 1.0 \mu \mathrm{m} \\
(1.6 \lambda)\end{array}$ & $\begin{array}{l}\mathrm{Ra} 270 \mathrm{~nm} \\
\quad(0.4 \lambda)\end{array}$ & $\begin{array}{c}\mathrm{Ra} 65 \mathrm{~nm} \\
\quad(0.1 \lambda)\end{array}$ & $\begin{array}{c}\mathrm{Ra} 11 \mathrm{~nm} \\
(0.02 \lambda)\end{array}$ \\
\hline \multicolumn{6}{|c|}{ Polytec OFV400 (single beam mode): Beam diameter $520 \mu \mathrm{m}$, Shaft diameter $15 \mathrm{~mm}$} \\
\hline $\begin{array}{l}\text { Typical scattered } \\
\text { light patterns }\end{array}$ & 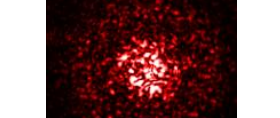 & & & 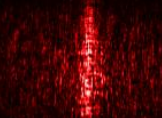 & \\
\hline $\begin{array}{l}\text { Mean level (std. } \\
\text { dev.) by order. } \\
\text { Orders } 1-10\end{array}$ & $\begin{array}{c}1.87 \\
(1.89)\end{array}$ & $\begin{array}{c}1.77 \\
(1.73)\end{array}$ & $\begin{array}{c}1.26 \\
(1.23)\end{array}$ & $\begin{array}{c}1.82 \\
(1.75)\end{array}$ & $\begin{array}{c}0.321 \\
(0.274)\end{array}$ \\
\hline $\begin{array}{l}\text { Mean level (std. } \\
\text { dev.) by order. } \\
\text { Orders } 11-20\end{array}$ & $\begin{array}{c}1.87 \\
(0.893)\end{array}$ & $\begin{array}{c}1.44 \\
(0.898)\end{array}$ & $\begin{array}{c}1.14 \\
(0.549)\end{array}$ & $\begin{array}{c}1.15 \\
(0.672)\end{array}$ & $\begin{array}{c}0.212 \\
(0.111)\end{array}$ \\
\hline $\begin{array}{l}\text { Mean level (std. } \\
\text { dev.) by order. } \\
\text { Orders } 21-30\end{array}$ & $\begin{array}{c}1.68 \\
(0.923)\end{array}$ & $\begin{array}{c}1.43 \\
(0.833)\end{array}$ & $\begin{array}{c}1.14 \\
(0.516)\end{array}$ & $\begin{array}{c}0.850 \\
(0.603)\end{array}$ & $\begin{array}{l}0.178 \\
(0.112)\end{array}$ \\
\hline $\begin{array}{l}\text { Mean level by } \\
\text { order. } \\
\text { Orders } 41-50\end{array}$ & 1.44 & 0.981 & 0.907 & 0.566 & 0.188 \\
\hline $\begin{array}{l}\text { Total RMS } \\
\text { level across } \\
\text { orders } 21-30\end{array}$ & 5.36 & 4.58 & 3.69 & 2.74 & 0.566 \\
\hline \multicolumn{6}{|c|}{ Polytec OFV302: Beam diameter $90 \mu \mathrm{m}$, Shaft diameter $15 \mathrm{~mm}$} \\
\hline $\begin{array}{l}\text { Typical scattered } \\
\text { light patterns }\end{array}$ & (3) & & & 15 & 1 \\
\hline $\begin{array}{l}\text { Mean level (std. } \\
\text { dev.) by order. } \\
\text { Orders } 1-10\end{array}$ & $\begin{array}{c}0.542 \\
(0.572)\end{array}$ & $\begin{array}{c}0.821 \\
(0.841)\end{array}$ & $\begin{array}{c}0.664 \\
(0.658)\end{array}$ & $\begin{array}{c}1.09 \\
(1.04)\end{array}$ & $\begin{array}{c}0.206 \\
(0.188)\end{array}$ \\
\hline $\begin{array}{l}\text { Mean level (std. } \\
\text { dev.) by order. } \\
\text { Orders } 11-20\end{array}$ & $\begin{array}{c}0.523 \\
(0.267)\end{array}$ & $\begin{array}{c}0.760 \\
(0.370)\end{array}$ & $\begin{array}{c}0.636 \\
(0.300)\end{array}$ & $\begin{array}{c}0.819 \\
(0.393)\end{array}$ & $\begin{array}{c}0.161 \\
(0.0771)\end{array}$ \\
\hline $\begin{array}{l}\text { Mean level (std. } \\
\text { dev.) by order. } \\
\text { Orders } 21-30\end{array}$ & $\begin{array}{c}0.530 \\
(0.260)\end{array}$ & $\begin{array}{c}0.664 \\
(0.344)\end{array}$ & $\begin{array}{c}0.674 \\
(0.318)\end{array}$ & $\begin{array}{c}0.535 \\
(0.250)\end{array}$ & $\begin{array}{c}0.144 \\
(0.0741)\end{array}$ \\
\hline $\begin{array}{l}\text { Mean level } \\
\text { by order. } \\
\text { Orders } 41-50\end{array}$ & 0.533 & 0.586 & 0.588 & 0.384 & 0.112 \\
\hline $\begin{array}{l}\text { Total RMS } \\
\text { level across } \\
\text { orders } 21-30\end{array}$ & 1.70 & 2.13 & 2.15 & 1.73 & 1.29 \\
\hline
\end{tabular}




\section{Figures}

Figure 1. Typical spectrum of apparent velocity dominated by speckle noise.

Figure 2. Schematic of transverse sensitivity measurement.

Figure 3. Schematic of tilt sensitivity measurement.

Figure 4. Tilt sensitivity, demonstrating the use of normalisation to remove the effect of vibration frequency.

Figure 5. Transverse velocity and typical (a) Measured velocity (b) Genuine velocity and (c) Apparent velocity. Beam diameter $520 \mu \mathrm{m}$, surface Ra $1.0 \mu \mathrm{m}$.

Figure 6. Transverse sensitivity maps for (a) $520 \mu \mathrm{m}$ beam diameter. (b) $90 \mu \mathrm{m}$ beam diameter. Surface displacement $420 \mu \mathrm{m}$ rms.

Figure 7. Typical data of speckle noise and angular velocity from tilting target surface.

Beam diameter $90 \mu \mathrm{m}$. Surface Ra $1.0 \mu \mathrm{m}$.

Figure 8. Tilt sensitivity map for (a) $520 \mu \mathrm{m}$ beam diameter. (b) $90 \mu \mathrm{m}$ beam diameter. Surface angular displacement $0.78^{\circ} \mathrm{rms}$.

Figure 9. Schematic of rotation sensitivity measurement.

Figure 10. Effect of shaft out-of-roundness on calculated rotation sensitivity. Beam diameters 520 $\mu \mathrm{m}$.

Figure 11. Typical measured velocities from (a) vibrometer A (b) vibrometer B and (c) the calculated differential velocity. Surface roughness Ra $1.0 \mu \mathrm{m}$, beam diameters $90 \mu \mathrm{m}$.

Figure 12. Rotation sensitivity from a surface treated with retro-reflective tape using a single measurement and a differential measurement (with $\sqrt{2}$ correction). Beam diameters $90 \mu \mathrm{m}$.

Figure 13. Rotation sensitivity for (a) $520 \mu \mathrm{m}$ beam diameter (b) $90 \mu \mathrm{m}$ beam diameter. $15 \mathrm{~mm}$ shaft diameter.

Figure 14. Schematic of parallel beam rotation sensitivity arrangement.

Figure 15. Parallel beam laser vibrometer rotation sensitivity. Shaft diameter $15 \mathrm{~mm}$, beam diameter $520 \mu \mathrm{m}$, surface coated with retro-reflective tape. 


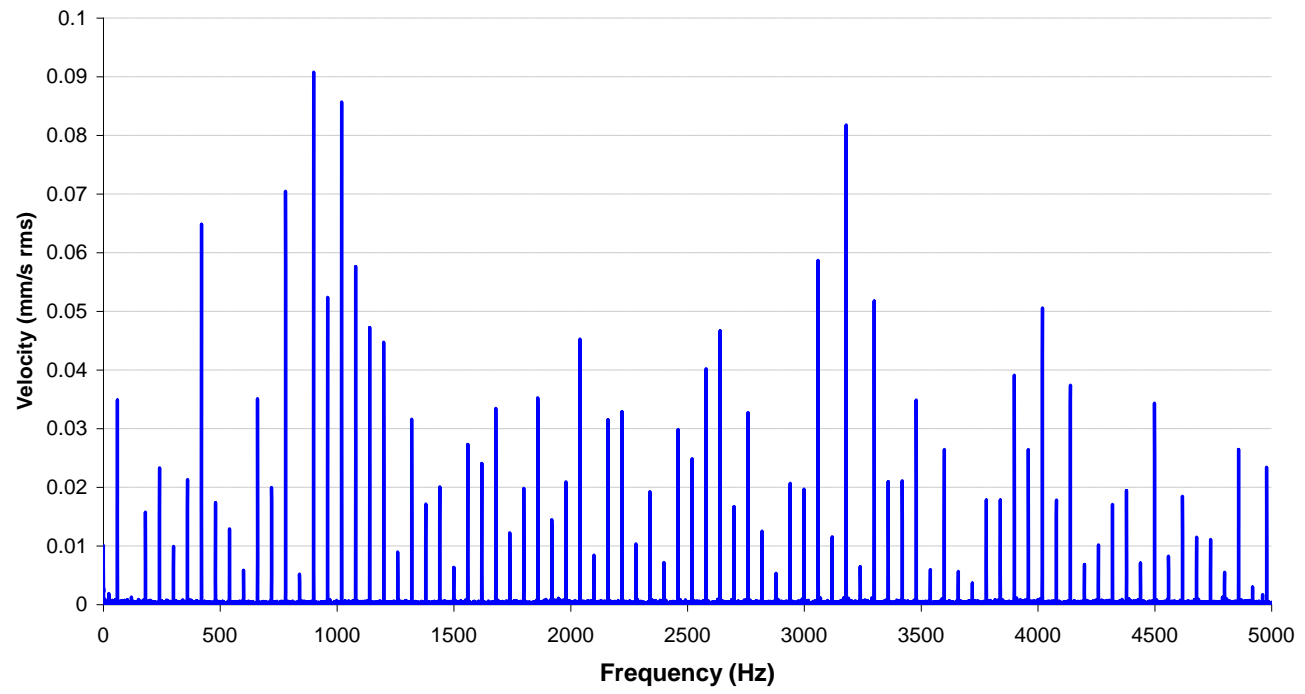

Figure 1. Typical spectrum of apparent velocity dominated by speckle noise. 

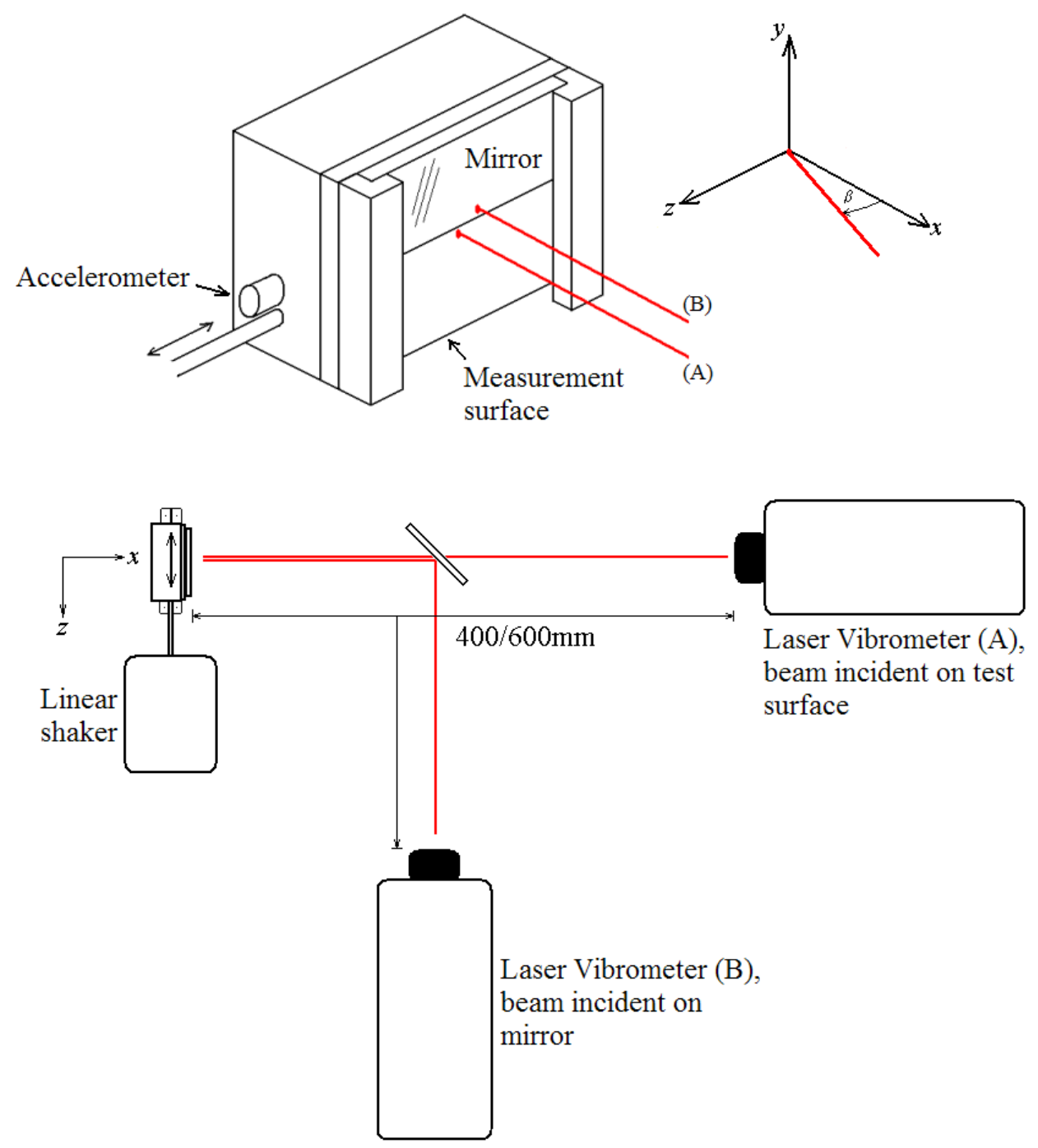

Figure 2. Schematic of transverse sensitivity measurement. 


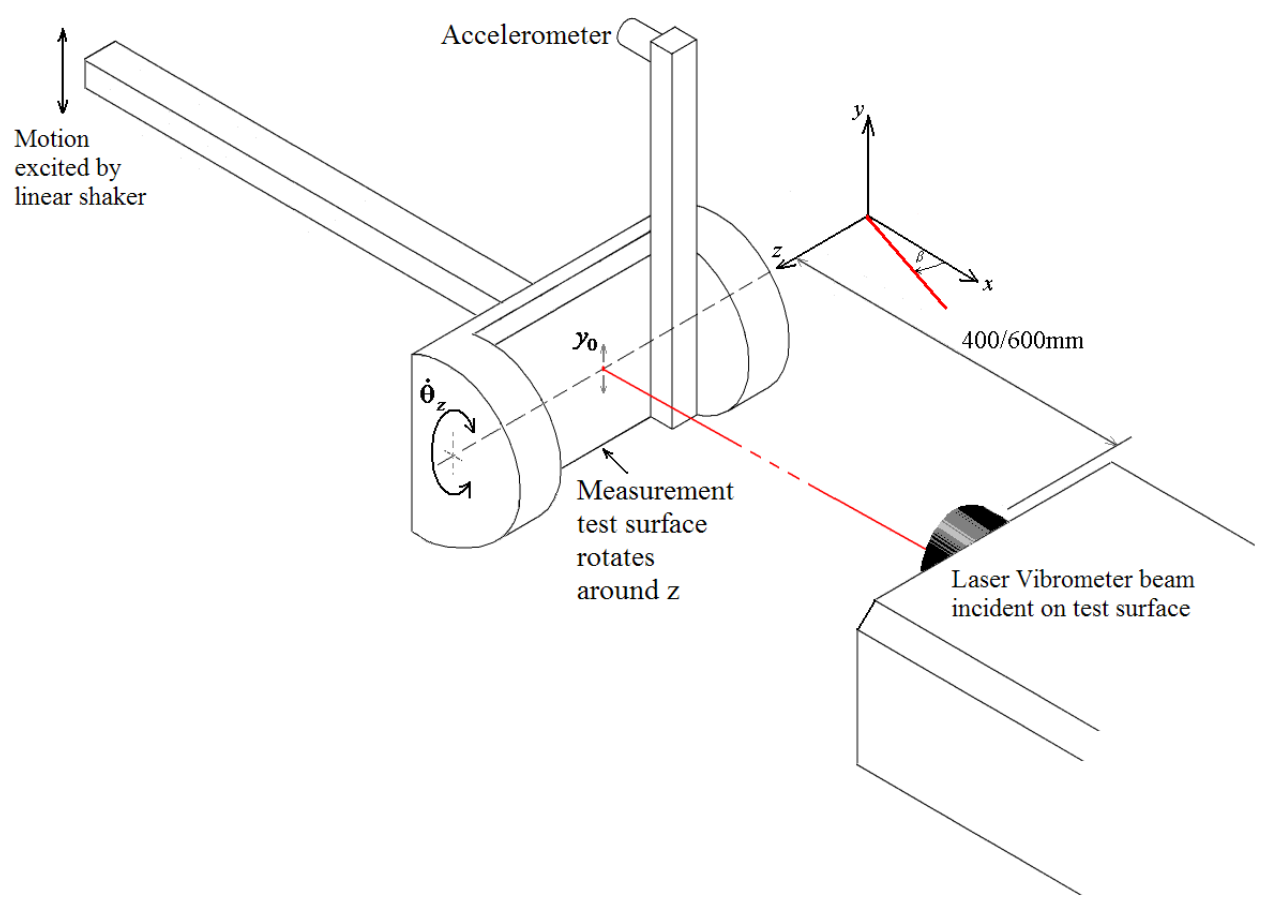

Figure 3. Schematic of tilt sensitivity measurement.

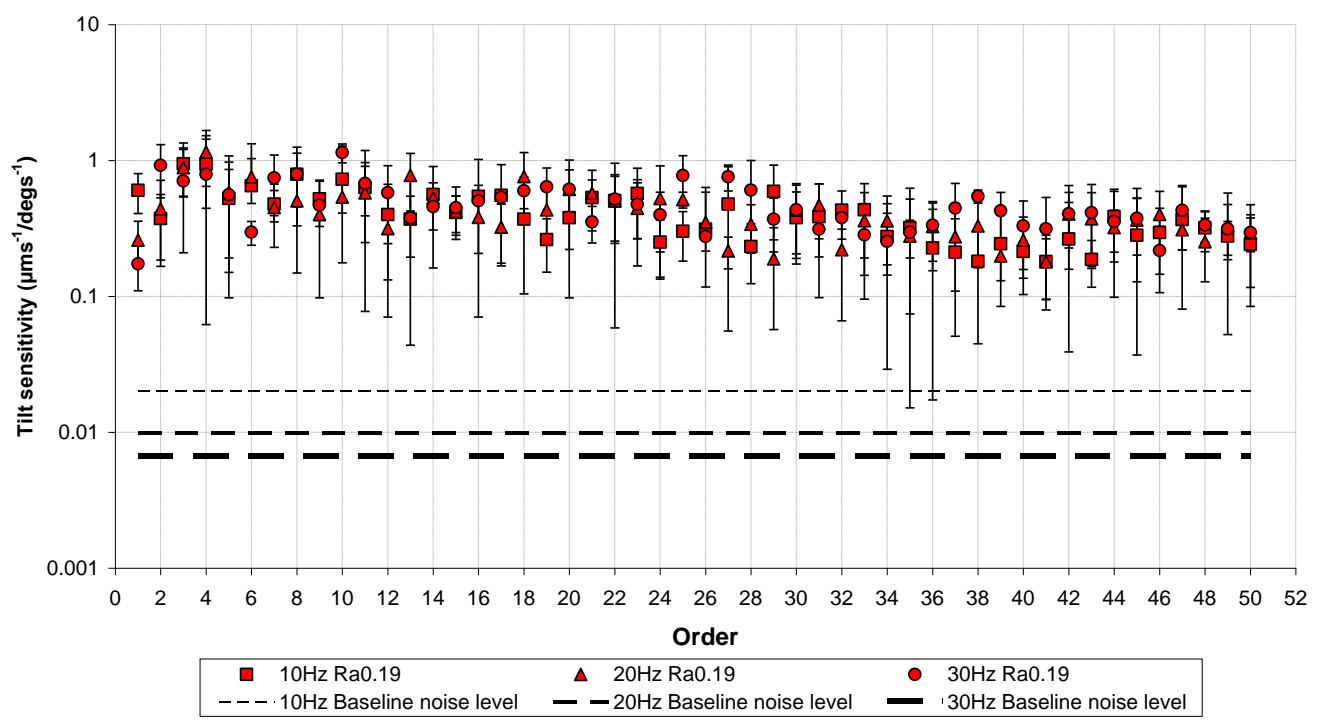

Figure 4. Tilt sensitivity, demonstrating the use of normalisation to remove the effect of vibration frequency. 


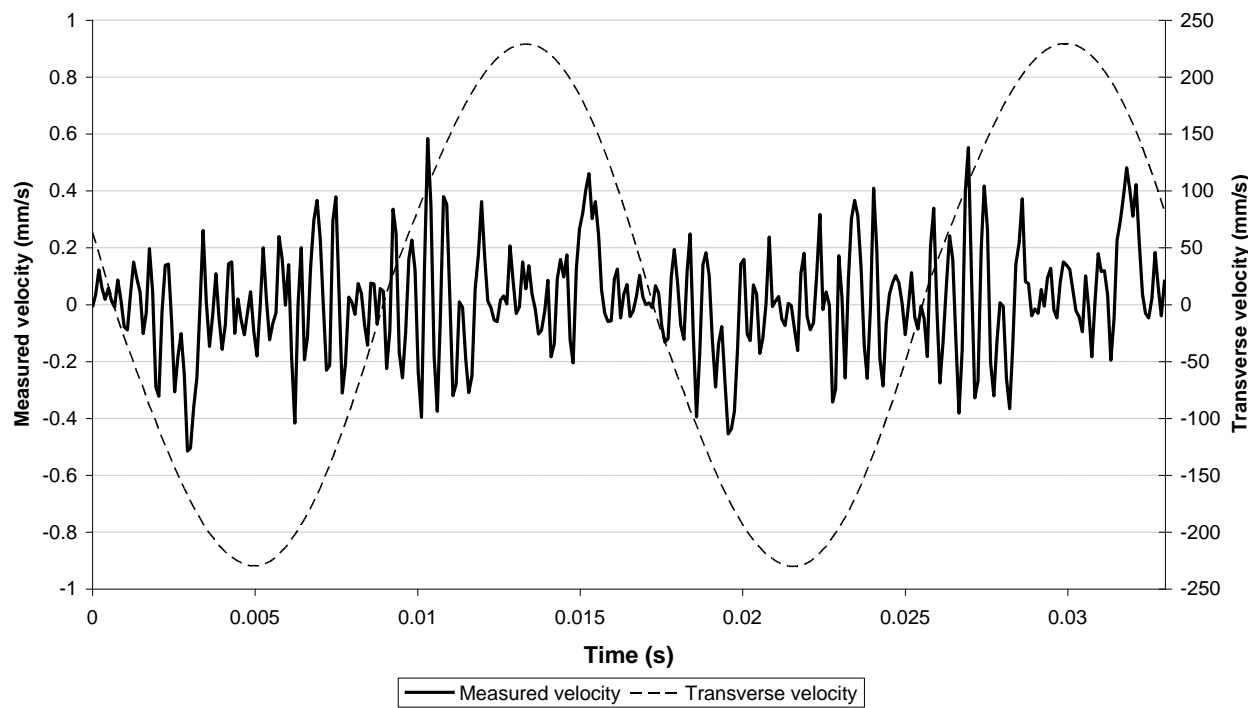

(a)

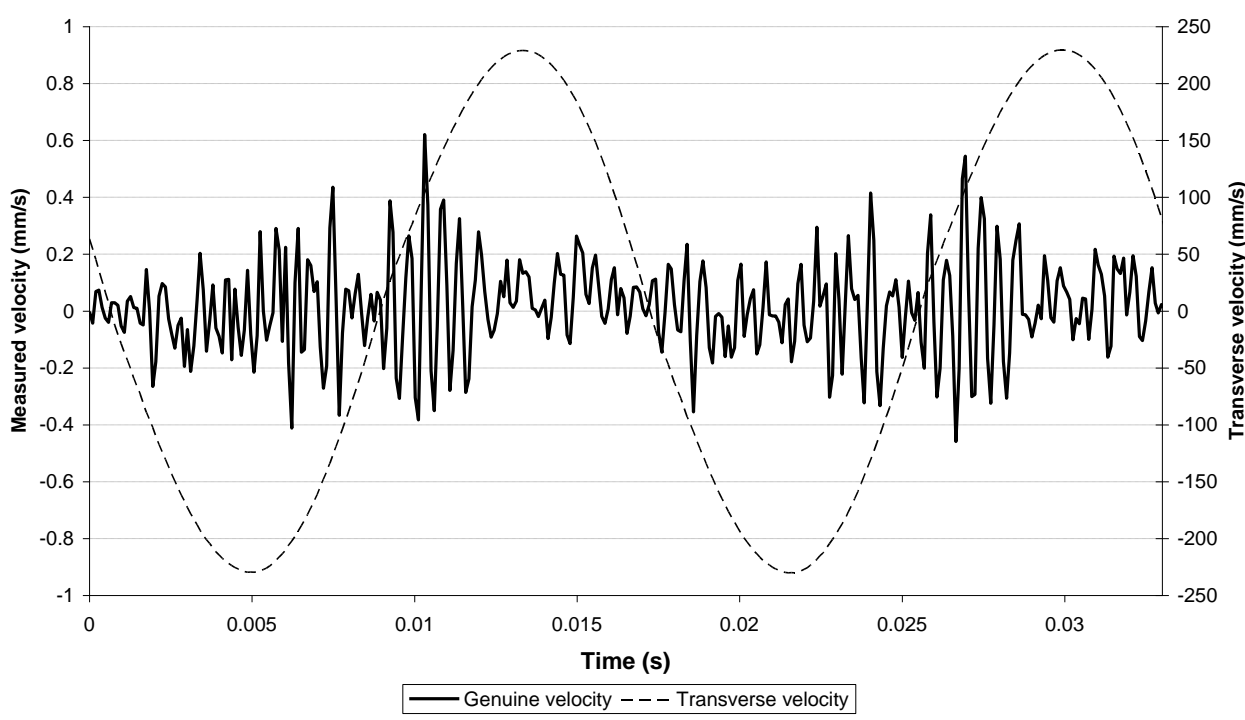

(b)

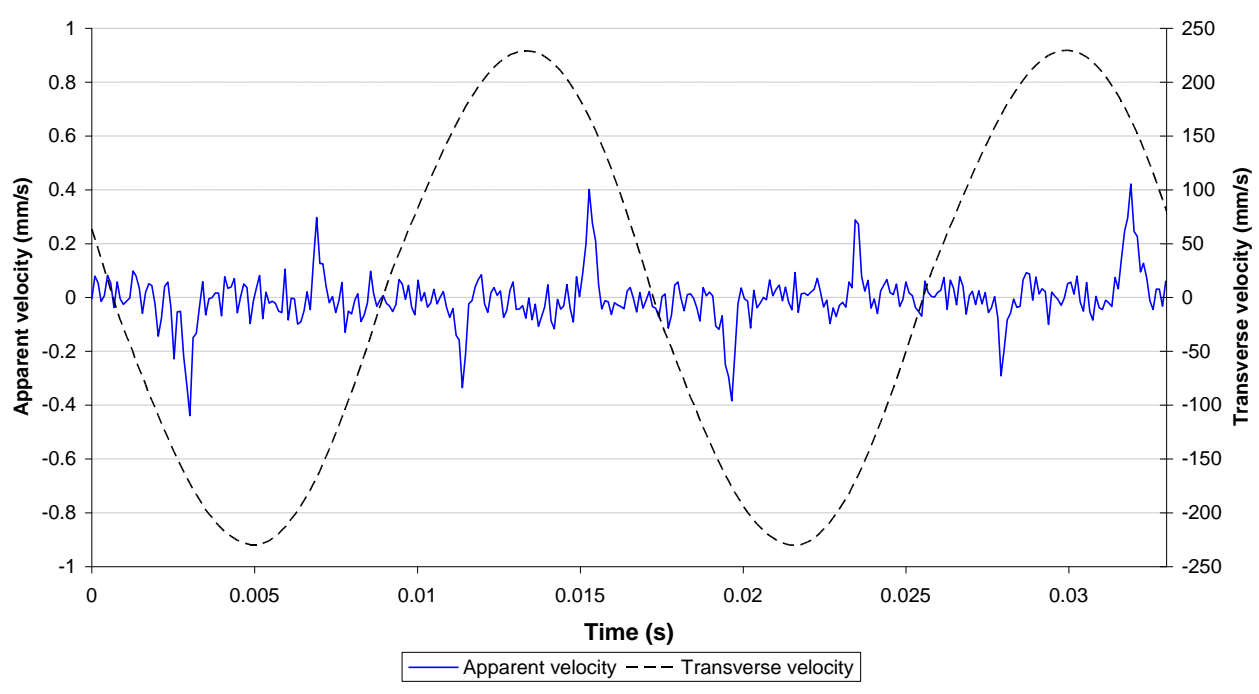

(c) 
Figure 5. Transverse velocity and typical (a) Measured velocity (b) Genuine velocity and (c) Apparent velocity. Beam diameter $520 \mu \mathrm{m}$, surface Ra $1.0 \mu \mathrm{m}$. 


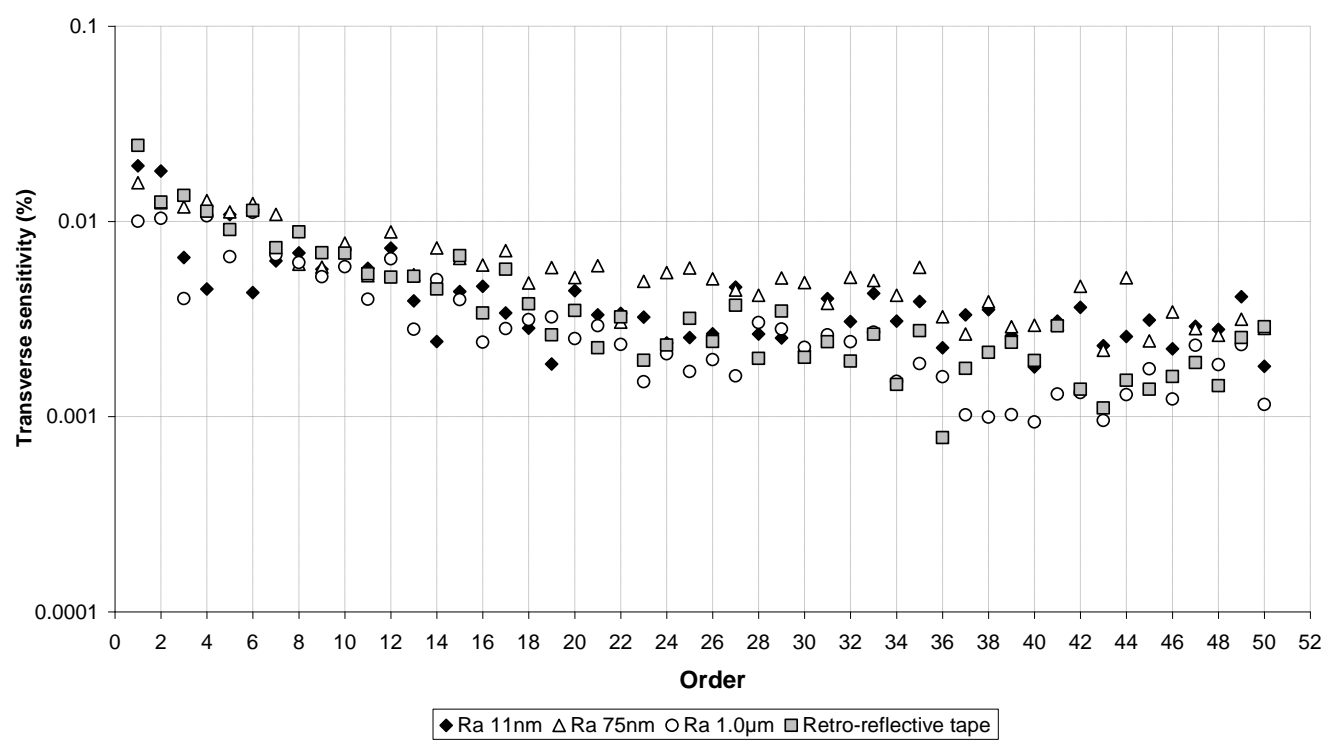

(a)

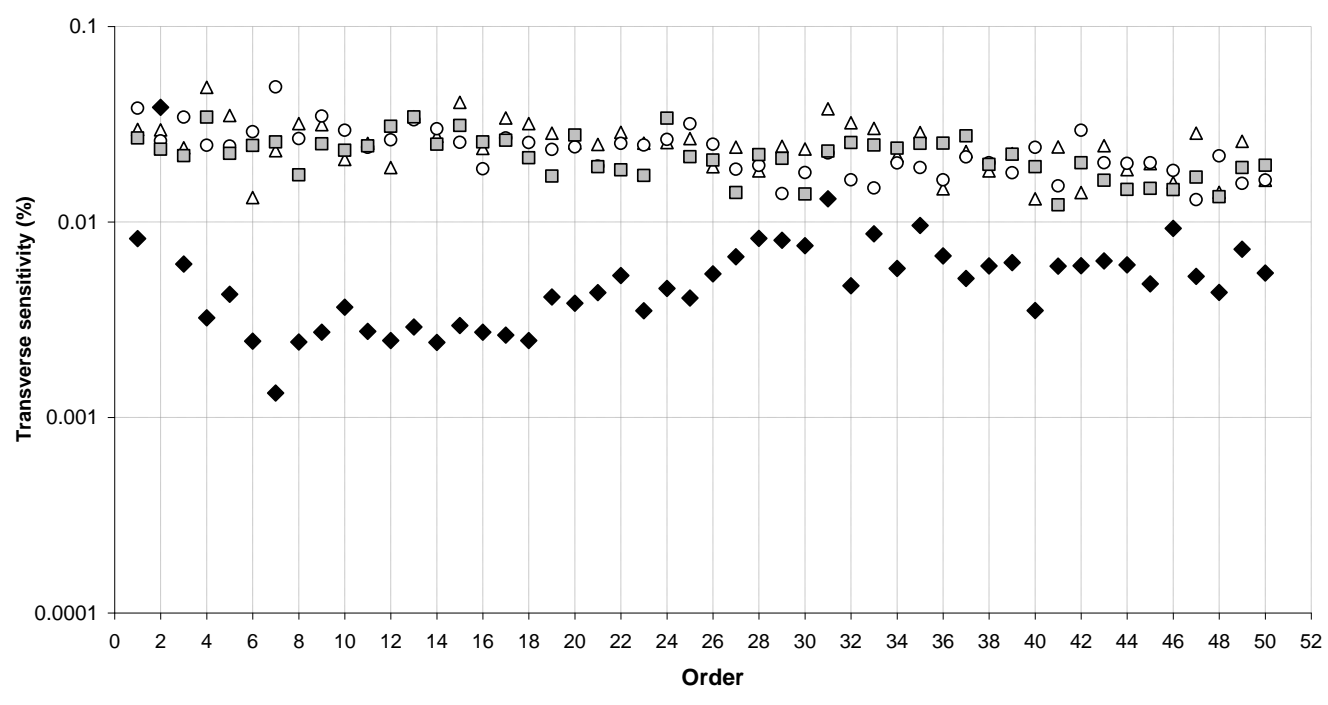

$\bullet$ Ra $11 \mathrm{~nm} \Delta \mathrm{Ra} 75 \mathrm{~nm}$ ORa $1.0 \mu \mathrm{m}$ 口Retro-reflective tape

(b)

Figure 6. Transverse sensitivity maps for (a) $520 \mu \mathrm{m}$ beam diameter. (b) $90 \mu \mathrm{m}$ beam diameter. Surface displacement $420 \mu \mathrm{m}$ rms. 


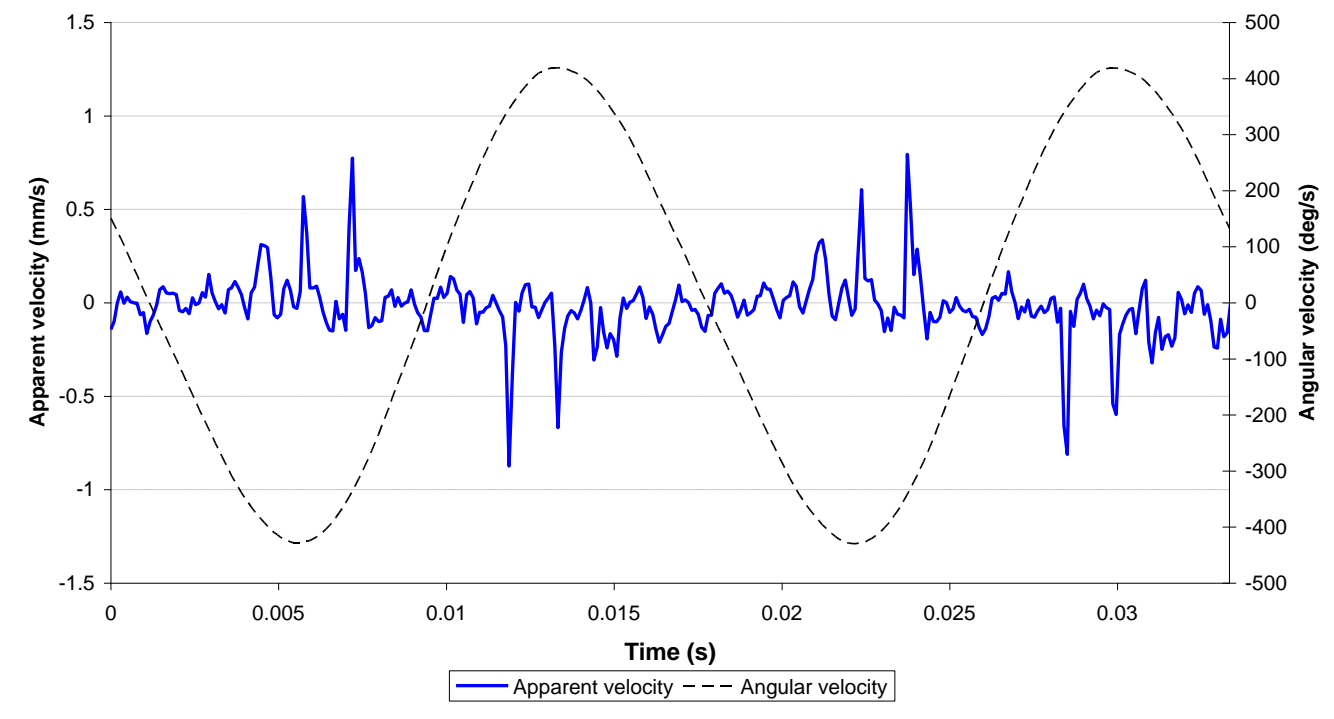

Figure 7. Typical data of speckle noise and angular velocity from tilting target surface. Beam diameter $90 \mu \mathrm{m}$. Surface Ra $1.0 \mu \mathrm{m}$. 


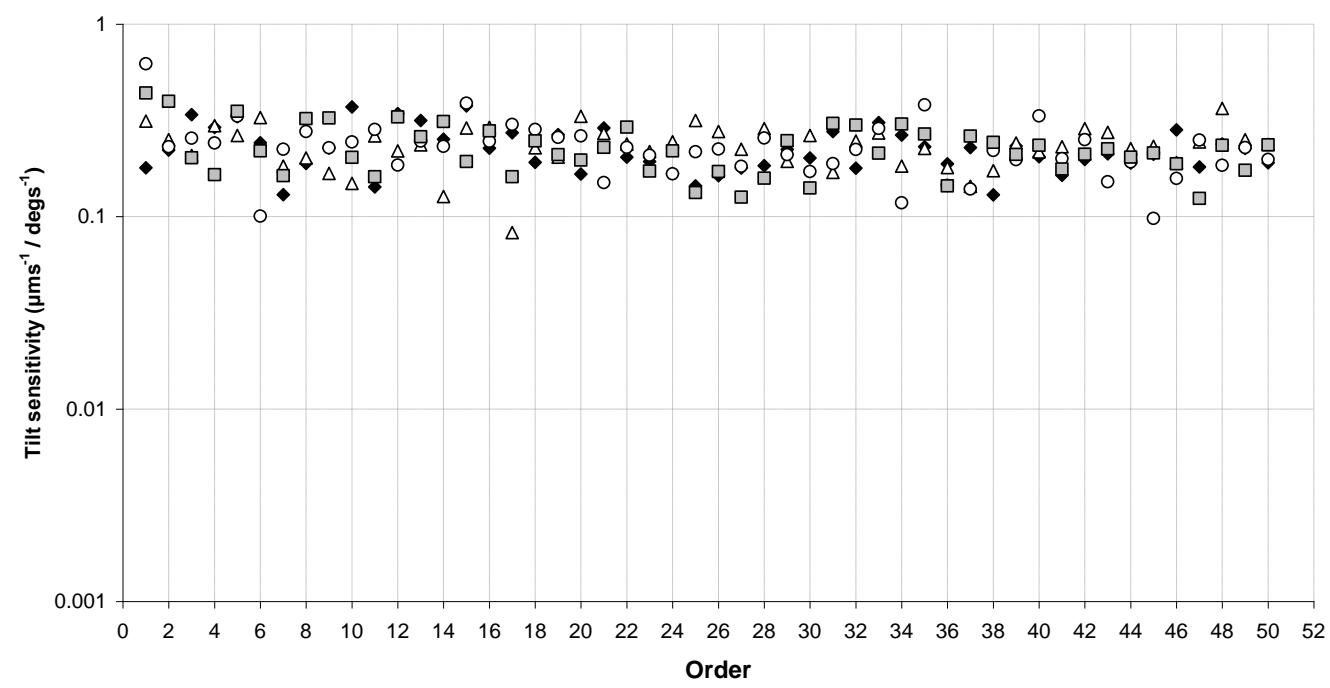

- Ra $11 \mathrm{~nm} \Delta$ Ra $75 \mathrm{~nm}$ oRa $1.0 \mu \mathrm{m}$ 口Retro-reflective tape

(a)

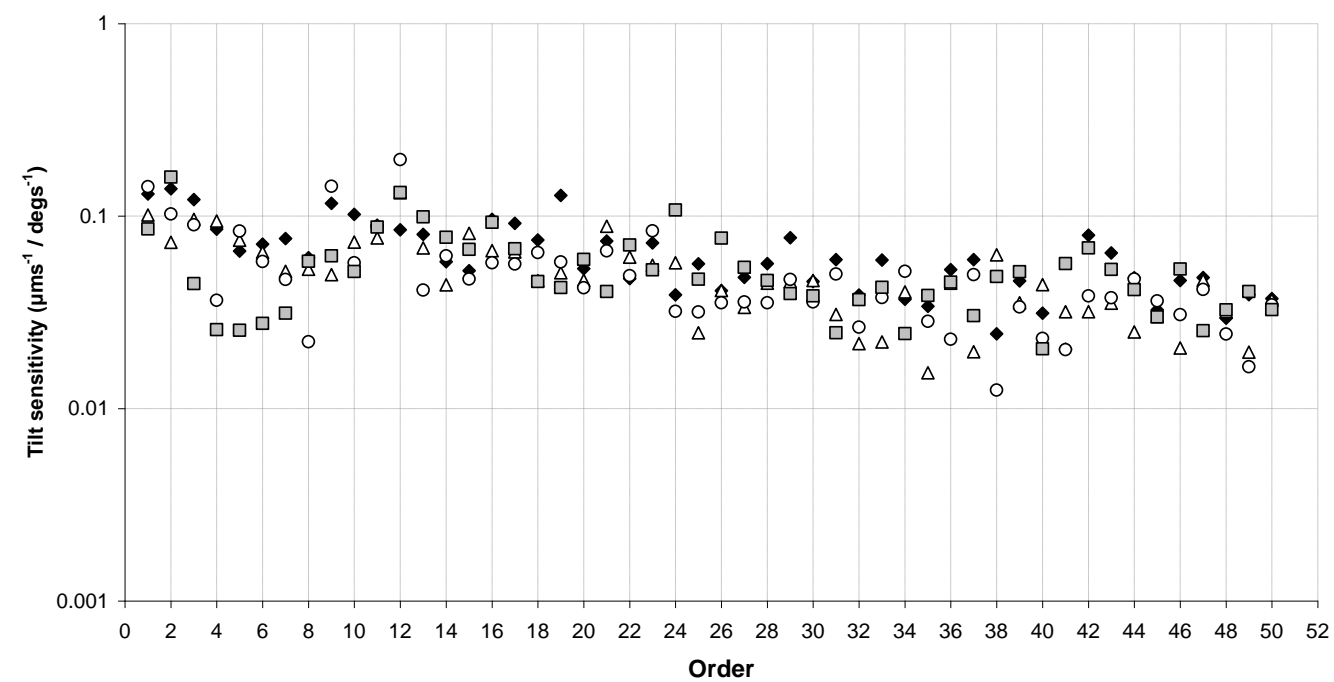

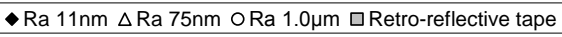

(b)

Figure 8. Tilt sensitivity map for (a) $520 \mu \mathrm{m}$ beam diameter. (b) $90 \mu \mathrm{m}$ beam diameter. Surface angular displacement $0.78^{\circ} \mathrm{rms}$. 


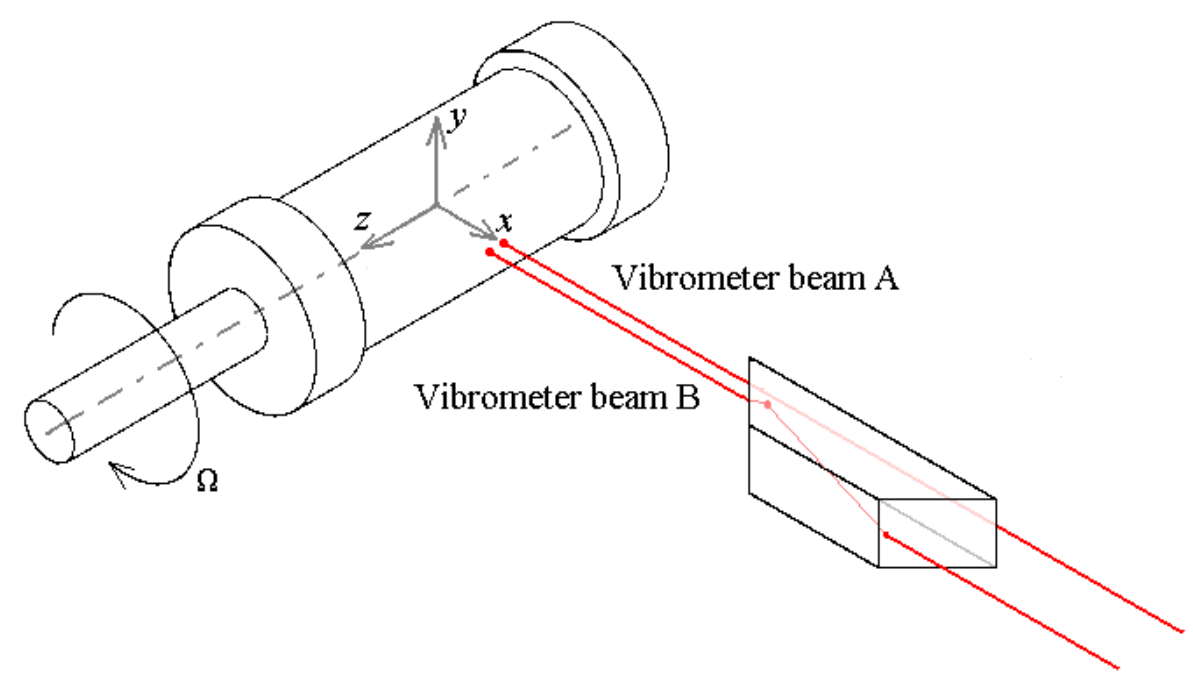

Figure 9. Schematic of rotation sensitivity measurement.

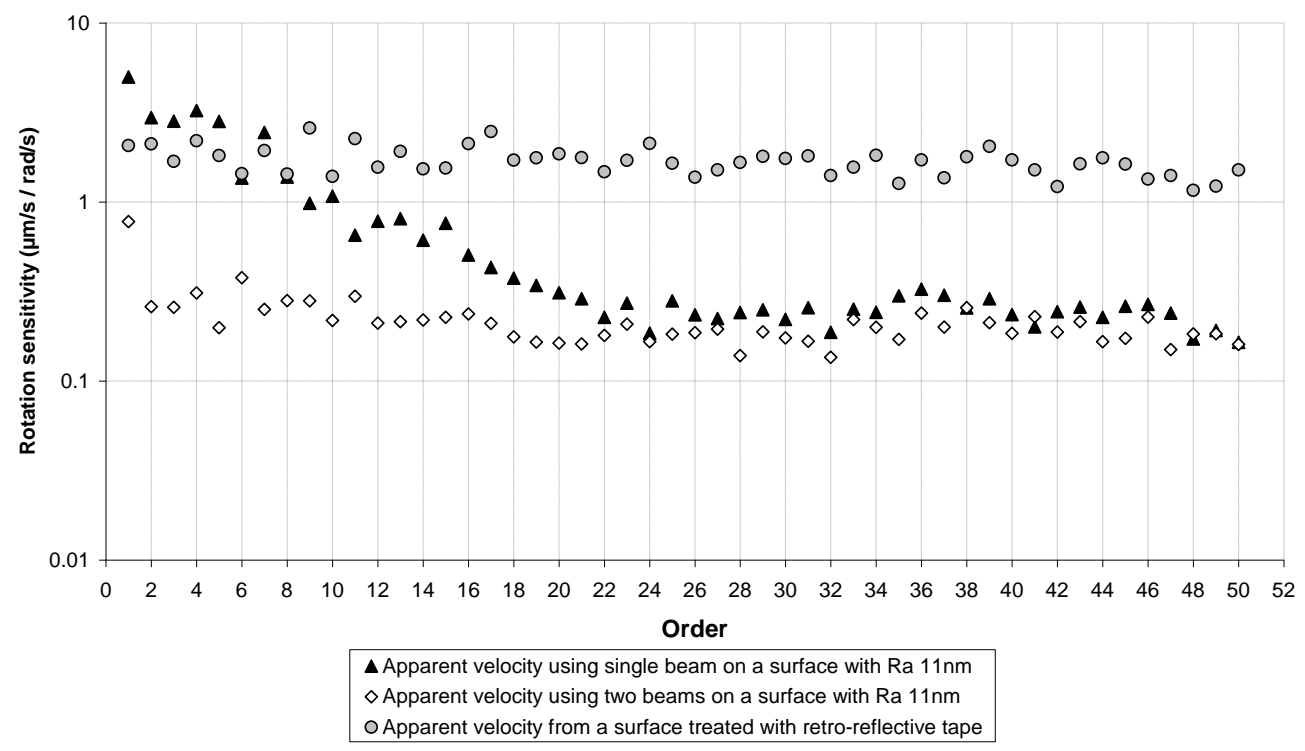

Figure 10. Effect of shaft out-of-roundness on calculated rotation sensitivity.

Beam diameters $520 \mu \mathrm{m}$. 


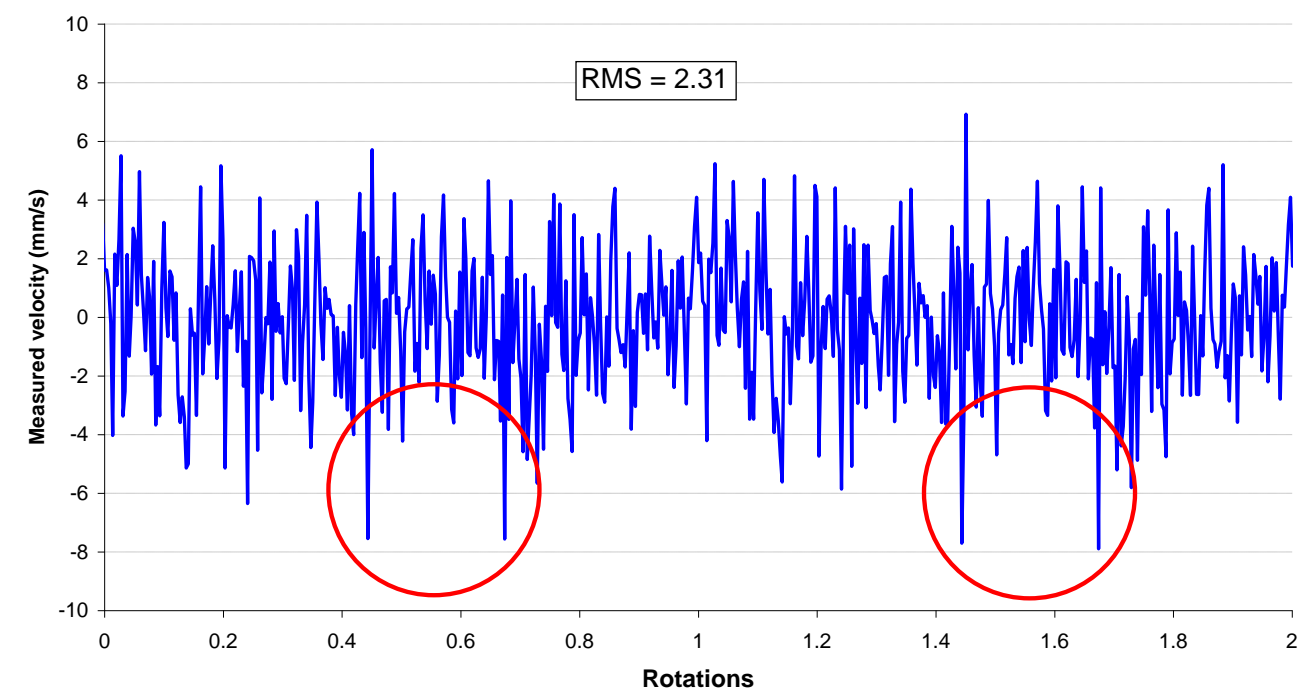

(a)

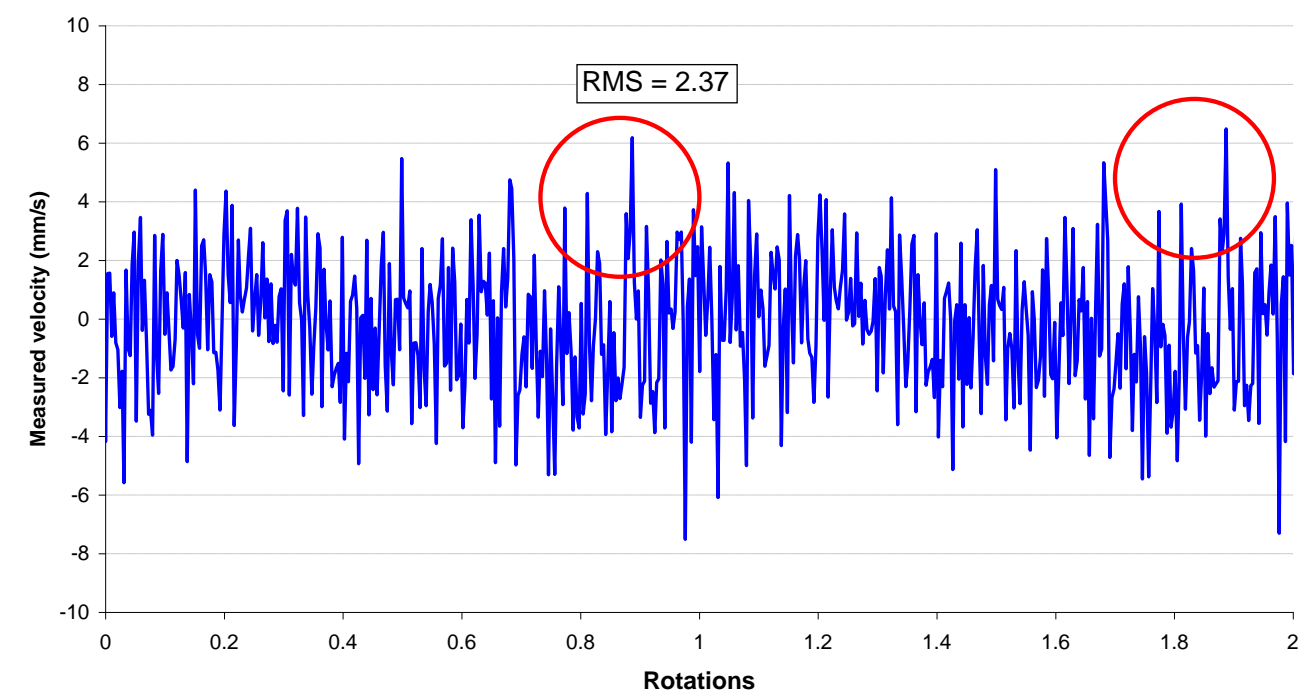

(b)

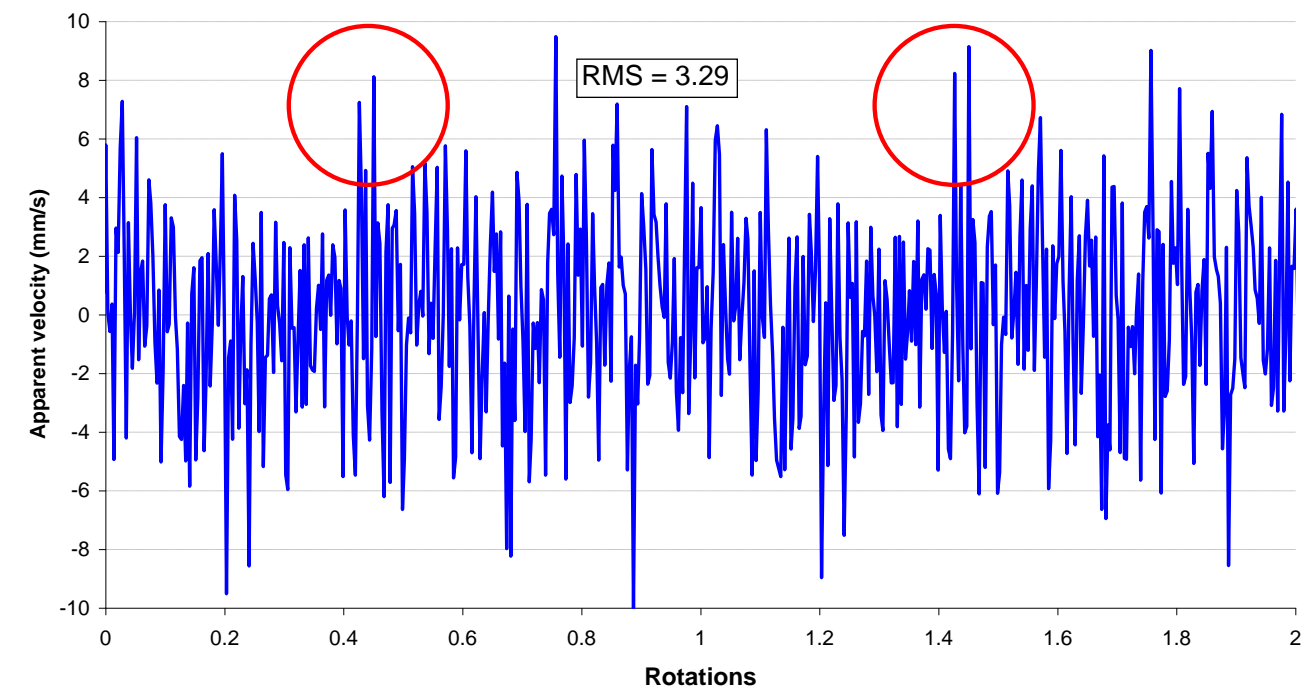

(c)

Figure 11. Typical measured velocities from (a) vibrometer A (b) vibrometer B and (c) the calculated differential velocity. Surface roughness Ra $1.0 \mu \mathrm{m}$, beam diameters $90 \mu \mathrm{m}$. 


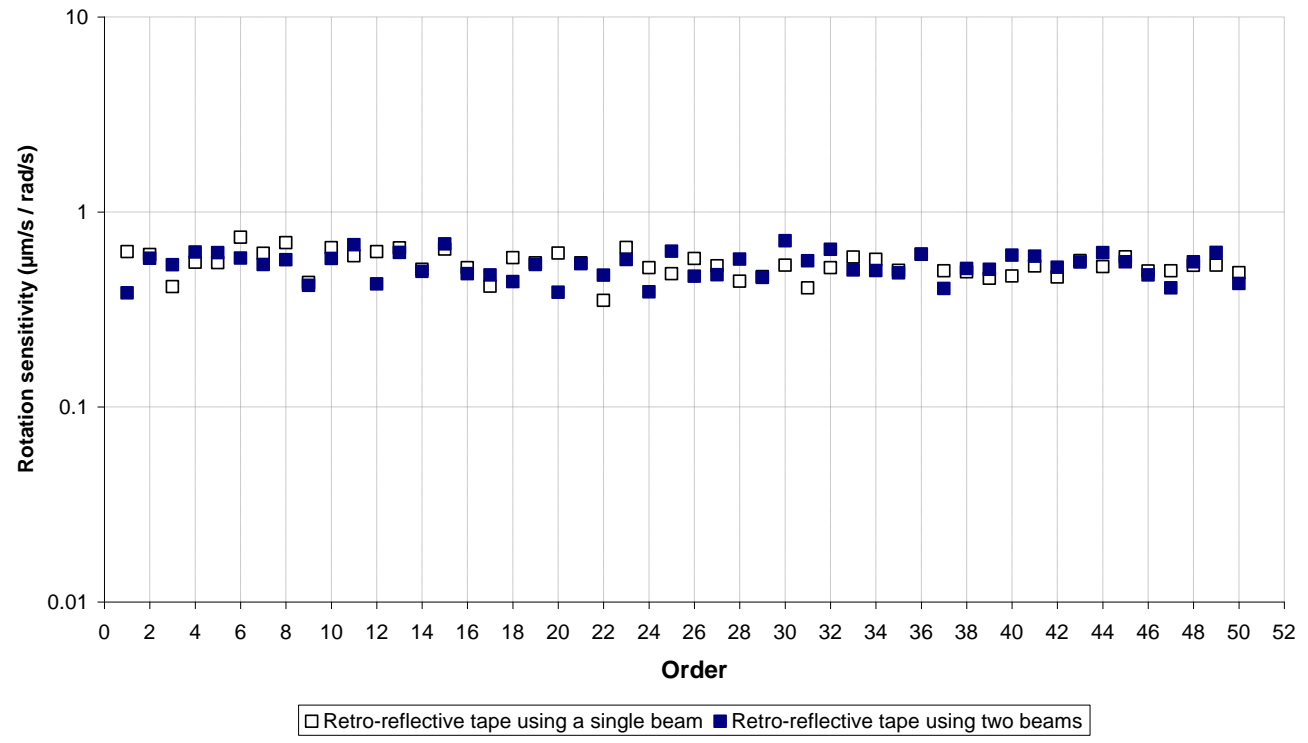

Figure 12. Rotation sensitivity from a surface treated with retro-reflective tape using a single measurement and a differential measurement (with $\sqrt{2}$ correction). Beam diameters $90 \mu \mathrm{m}$. 


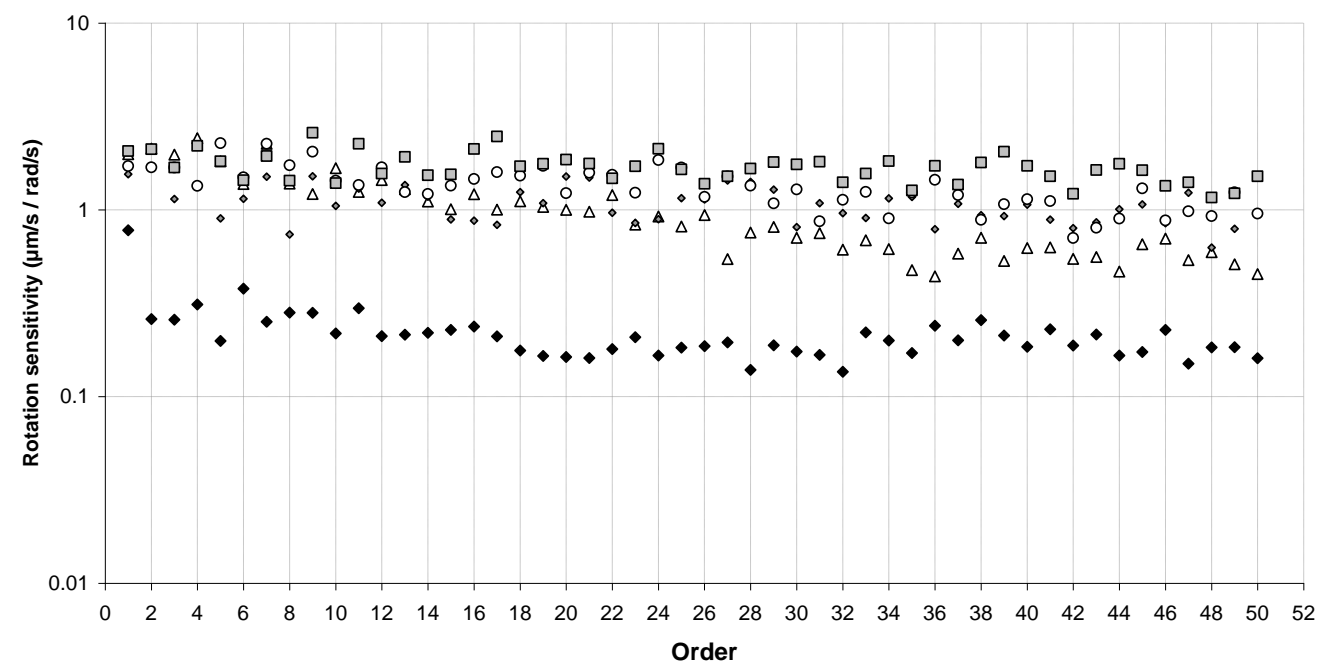

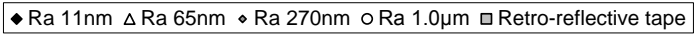

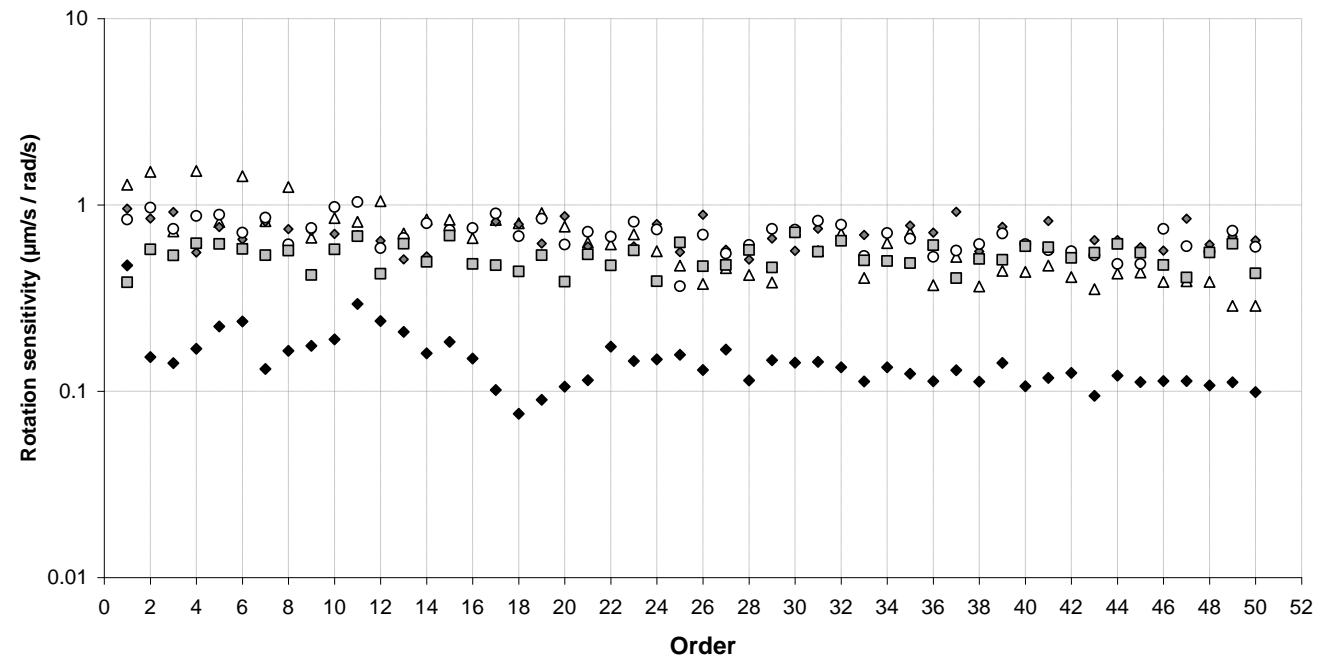

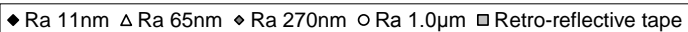

(b)

Figure 13. Rotation sensitivity for (a) $520 \mu \mathrm{m}$ beam diameter (b) $90 \mu \mathrm{m}$ beam diameter.

$15 \mathrm{~mm}$ shaft diameter. 


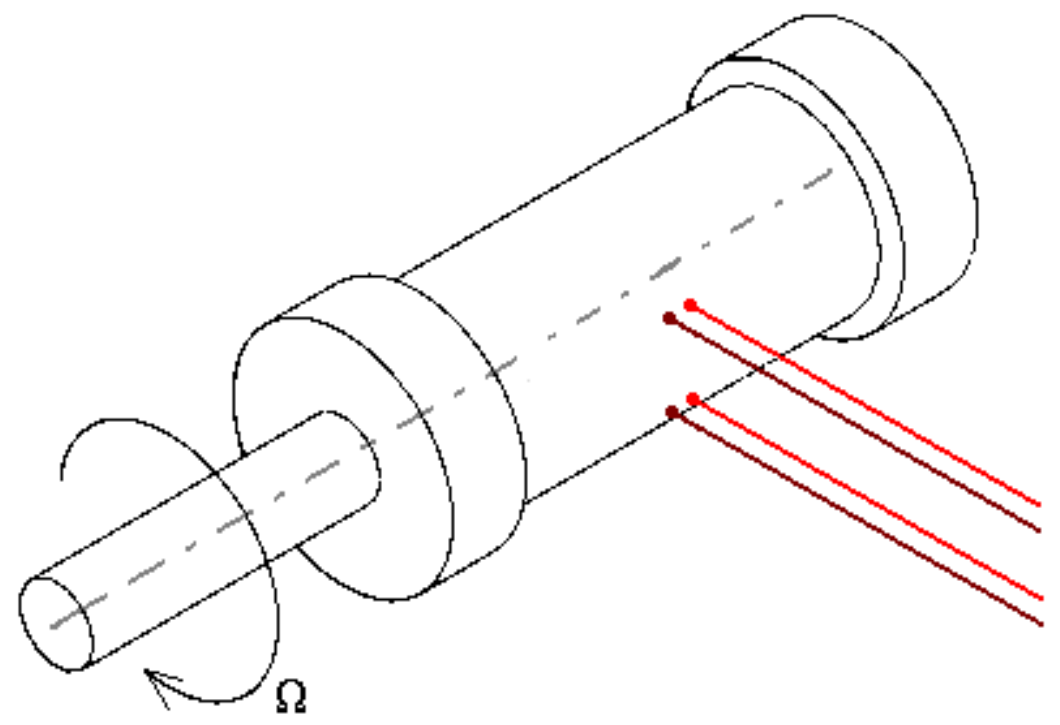

Figure 14. Schematic of parallel beam rotation sensitivity arrangement.

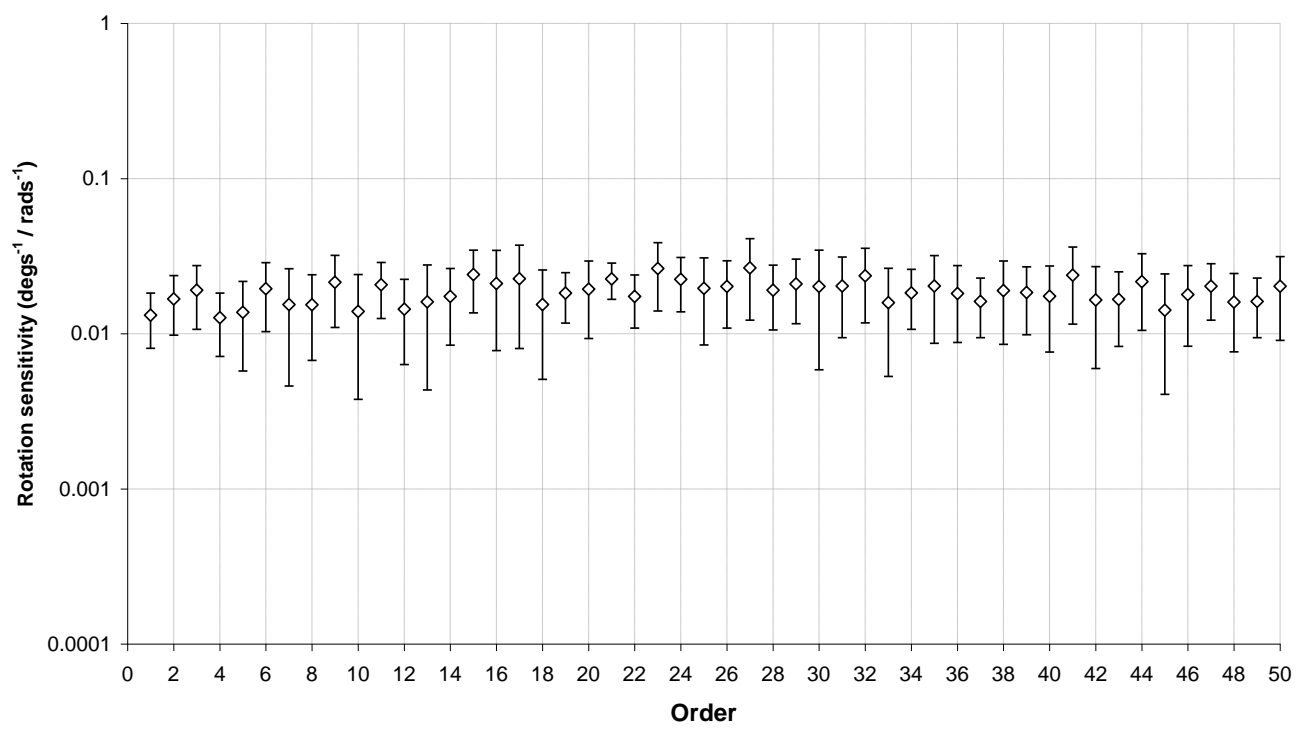

Figure 15. Parallel beam laser vibrometer rotation sensitivity. Shaft diameter $15 \mathrm{~mm}$, beam diameter $520 \mu \mathrm{m}$, surface coated with retro-reflective tape. 


\section{References}

[1] Goodman J W 1976 Some fundamental properties of speckle Journal of the Optical Society of America 66(11) 1145-1150

[2] McDevitt T E and Vikram C S 1997 An investigation of pseudo-vibration signals in dual beam laser vibrometry Review of Scientific Instruments 68(4) 1753-1755

[3] Strean R F, Mitchell L D and Barker A J 1998 Global noise characteristics of a laser Doppler vibrometer - I. Theory Optics and Lasers in Engineering 30(2) 127-139

[4] Vass J, Smid R, Randall R B, Sovka P and Cristalli C 2008 Avoidance of speckle noise in laser vibrometry by the use of kurtosis ratio: Application to mechanical fault diagnostics Mechanical Systems and Signal Processing 22(3) 647-671

[5] Wang C C, Trivedi S, Jin F, Swaminathan V, Rodriguez P, and Prasad N S 2009 High sensitivity pulsed laser vibrometer and its application as a laser microphone Applied Physics Letters 94(5) Art. No. 051112

[6] Totems J, Jolivet V, Ovarlez J-P and Martin N 2010 Advanced signal processing methods for pulsed laser vibrometry Applied Optics 49(20) 3967-3979

[7] Rothberg S J, Baker J R and Halliwell N A 1989 Laser vibrometry: Pseudo-vibrations Journal of Sound \& Vibration 135(3) 516-22

[8] Rothberg S J 2006 Numerical simulation of speckle noise in laser vibrometry Applied Optics 4519 4523-33

[9] Drew S J and Stone B J 1997 Torsional (rotational) vibration: Excitation of small rotating machines Journal of Sound and Vibration 201(4) 437-463

[10] Jakobsen M L, Harvey D, Carolan T A, Barton J S, Jones J D C and Reuben R L 1999 Optical probing of acoustic emission from a rotating tool holder with a Sagnac interferometer Proceedings of the Institution of Mechanical Engineers Part B Journal of Engineering Manufacture 213(2) 171-181

[11] Aranchuk V, Lal A, Hess C and Sabatier J M 2006 Multi-beam laser Doppler vibrometer for landmine detection Optical Engineering 45(10) Art. No. 104302

[12] Chen F and McKillip D 2007 Measurement and analysis of vibration and deformation using laser metrology for automotive application Proceedings of the Institution of Mechanical Engineers Part D Journal of Automobile Engineering 221(D6) 725-738

[13] Agostinelli G and Paone N Repeatability and reproducibility of characteristic features measured by laser Doppler vibrometry for on-line diagnostics Proceedings of the Eighth International Conference on Vibration Measurements by Laser Techniques: Advances and Applications, E.P.Tomasini (ed), International Society for Optical Engineering, Ancona, Italy, 2008, Paper 70981C 
[14] O'Malley P, Woods T, Judge J and Vignola J 2009 Five-axis scanning laser vibrometry for three-dimensional measurements of non-planar surfaces Measurement Science and Technology 20115901

[15] BS ISO 16063-31:2009 Methods for the calibration of vibration and shock transducers: Testing of transverse vibration sensitivity

[16] Sumali H and Allen M S Apparent nonlinear effect of the microscope on the laser Doppler vibrometer Proceedings of the Eighth International Conference on Vibration Measurements by Laser Techniques: Advances and Applications, E.P.Tomasini (ed), International Society for Optical Engineering, Ancona, Italy, 2008, Paper 709817

[17] Halkon B J and Rothberg S J 2006 Vibration measurements using continuous scanning laser vibrometry: Advanced aspects in rotor applications Mechanical Systems and Signal Processing 20(6) 1286-1299

[18] Halkon B J and Rothberg S J 2006 Rotor vibration measurements using laser Doppler vibrometry: Essential post-processing for resolution of radial and pitch/yaw vibrations Journal of Vibration and Acoustics - Transactions of the ASME 128(1) 8-20

[19] Martin P and Rothberg S J 'Differential measurements using two laser rotational vibrometers: dynamic backlash Proceedings of the Seventh International Conference on Vibration Measurements by Laser Techniques: Advances and Applications, E.P.Tomasini (ed), International Society for Optical Engineering, Ancona, Italy, 2006, Paper 6345-23

[20] Aranchuk V, Lal A K, Hess C F, Sabatier J M, Burgett R D, Aranchuk I and Mayo W T Speckle noise in a continuously scanning multi-beam laser Doppler vibrometer for acoustic landmine detection Proceedings of the Society of Photo-Optical Instrumentation Engineers (SPIE) Vol. 6217 Conference on Detection and Remediation Technologies for Mines and Minelike Targets XI, Kissimmee, US, 2006, Art. no. 621716

[21] Martarelli M and Ewins D J 2006 Continuous scanning laser Doppler vibrometry and speckle noise occurrence Mechanical Systems and Signal Processing 20(8) 2277-2289

[22] Drabenstedt A Quantification of displacement and velocity noise in vibrometer measurements on transversely moving or rotating surfaces Proceedings of the Society of Photo-Optical Instrumentation Engineers (SPIE) Vol. 6616 Conference on Optical Measurement Systems for Industrial Inspection V, Munich, Germany, 2007, Art. no. 661632

[23] Bell J R and Rothberg S J 2000 Laser vibrometers and contacting transducers, target rotation and 6 degree-of-freedom vibration: What do we really measure? Journal of Sound and Vibration 237(2) 245-61

[24] Bell J R and Rothberg S J 2000 Rotational vibration measurements using laser doppler vibrometry: Comprehensive theory and practical applications Journal of Sound and Vibration 238(4) 673-690 
[25] Dainty J C 1984 Laser Speckle and Related Phenomena Springer-Verlag

[26] Martin P and Rothberg S J 2009 Introducing speckle noise maps for laser vibrometry Optics and Lasers in Engineering 47(3-4) 431-42

[27] Tatar K, Rantatalo M and Gren P 2007 Laser vibrometry measurements of an optically smooth rotating spindle Mechanical Systems and Signal Processing 21(4) 1739-1745

[28] Tatar K and Gren P 2008 Measurement of milling tool vibrations during cutting using laser vibrometry International Journal of Machine Tools \& Manufacture 48(3-4) 380-387

[29] Gade S and Herlufsen H 1987 Use of Weighting Functions in DFT/FFT Analysis (Part II) Appendix F: Picket Fence Effect Brüel and Kjar Technical Review 43 28-35

[30] Khan A Z, Stanbridge A B and Ewins D J 1999 Detecting damage in vibrating structures with a scanning LDV Optics and Lasers in Engineering 32(6) 583-592

[31] Allen M S and Sracic M W 2010 A new method for processing impact excited continuousscan laser Doppler vibrometer measurements Mechanical Systems and Signal Processing 24(3) 721-735

[32] Sracic M W and Allen M S Experimental Investigation of the Effect of Speckle Noise on Continuous Scan Laser Doppler Vibrometer Measurements Proceedings of the 27th International Modal Analysis Conference (IMAC XXVII) on CD-ROM, Orlando, Florida, Feb. 2009

[33] Di Sante R and Rossi G L 2001 A new approach to the measurement of transverse vibration and acoustic radiation of automotive belts using laser Doppler vibrometry and acoustic intensity techniques Measurement Science and Technology 12(4) 525-533

[34] Hocknell A, Jones R and Rothberg S J 1998 Remote vibration measurements: Compensation of waveform distortion due to whole body translations Journal of Sound and Vibration 214(2) 285-307

[35] The Torsional Vibration Meter Type 2523, Brüel \& Kjær Product Data BP 0958.

[36] Drew S J and Stone B J 1997 Removal of speckle harmonics in laser torsional vibrometry Mechanical Systems and Signal Processing 11(5) 773-776 